\title{
TRF1 negotiates TTAGGG repeat- associated replication problems by recruiting the BLM helicase and the TPP1/POT1 repressor of ATR signaling
}

\author{
Michal Zimmermann, ${ }^{1,2}$ Tatsuya Kibe, ${ }^{1}$ Shaheen Kabir, ${ }^{1}$ and Titia de Lange ${ }^{1}$ \\ ${ }^{1}$ Laboratory for Cell Biology and Genetics, The Rockefeller University, New York, New York 10065, USA; ${ }^{2}$ Central European \\ Institute of Technology, Masaryk University, Brno 625 00, Czech Republic
}

The semiconservative replication of telomeres is facilitated by the shelterin component TRF1. Without TRF1, replication forks stall in the telomeric repeats, leading to ATR kinase signaling upon S-phase progression, fragile metaphase telomeres that resemble the common fragile sites (CFSs), and the association of sister telomeres. In contrast, TRF1 does not contribute significantly to the end protection functions of shelterin. We addressed the mechanism of TRF1 action using mouse conditional knockouts of BLM, TRF1, TPP1, and Rap1 in combination with expression of TRF1 and TIN2 mutants. The data establish that TRF1 binds BLM to facilitate lagging but not leading strand telomeric DNA synthesis. As the template for lagging strand telomeric DNA synthesis is the TTAGGG repeat strand, TRF1-bound BLM is likely required to remove secondary structures formed by these sequences. In addition, the data establish that TRF1 deploys TIN2 and the TPP1/POT1 heterodimers in shelterin to prevent ATR during telomere replication and repress the accompanying sister telomere associations. Thus, TRF1 uses two distinct mechanisms to promote replication of telomeric DNA and circumvent the consequences of replication stress. These data are relevant to the expression of CFSs and provide insights into TIN2, which is compromised in dyskeratosis congenita (DC) and related disorders.

[Keywords: telomere; shelterin; TRF1; BLM; replication; G quadruplex]

Supplemental material is available for this article.

Received August 21, 2014; revised version accepted October 6, 2014.

Telomeres pose two major challenges to cells. The first involves the end replication problem, which is solved by the ability of telomerase to maintain telomeric repeats at chromosome ends (Greider and Blackburn 1985). The second challenge pertains to the end protection problem, which is solved through repression of DNA damage signaling and double-strand break (DSB) repair by the shelterin protein complex bound to the telomeric repeats (de Lange 2009). It has recently emerged that the telomeric repeats come with their own challenges due to problems arising during semiconservative DNA replication. The shelterin subunit TRF1 is dedicated to preventing these replication problems and/or counteracting their deleterious consequences (Martinez et al. 2009; Sfeir et al. 2009).

The TRF1 homodimers specifically bind double-stranded TTAGGG repeats with C-terminal Myb/SANT domains

Corresponding author: delange@mail.rockefeller.edu

Article published online ahead of print. Article and publication date are online at http://www.genesdev.org/cgi/doi/10.1101/gad.251611.114. Freely available online through the Genes \& Development Open Access option. and thus accumulate at telomeres and interstitial TTAGGG repeats (Chong et al. 1995; for review, see Palm and de Lange 2008). TRF1 is connected to the rest of shelterin through TIN2, which binds to the TRFH dimerization domain of TRF1 (Kim et al. 1999; Chen et al. 2008). TIN2 also binds to TRF2 and, importantly, interacts with TPP1, thereby mediating the recruitment of POTla and POT1b that is required for telomere protection (for review, see Palm and de Lange 2008; Takai et al. 2011; Frescas and de Lange 2014c). Both POT1 proteins associate with single-stranded TTAGGG repeats, where their engagement prevents activation of the ATR kinase (primarily a function of POTla) and regulates the formation of the $3^{\prime}$ telomeric overhang (a function of POT1b) (Hockemeyer et al. 2006, 2008; Denchi and de Lange 2007; He et al. 2009; Wu et al. 2012). TRF1 and TRF2 can each support the functions of POTla and POT1b

(C) 2014 Zimmermann et al. This article, published in Genes \& Development, is available under a Creative Commons License (Attribution-NonCommercial 4.0 International), as described at http://creativecommons.org/licenses/by-nc/4.0/. 
through their recruitment of TIN2 (and thus the TPP1/ POT1 heterodimers), provided that enough TIN2 is present at telomeres (Frescas and de Lange 2014a).

DNA combing experiments showed that the majority of telomeres are replicated by forks moving toward the telomere end using the TTAGGG repeat strand as the template for lagging strand DNA synthesis (Sfeir et al. 2009). When TRF1 is deleted from mouse cells, replication frequently stalls near the subtelomeric/telomeric junction. These replication problems are correlated with the appearance of the so-called fragile telomere phenotype in which multiple telomeric fluorescence in situ hybridization (FISH) signals appear at a single chromatid end, giving telomeres a broken or incompletely condensed appearance (Martinez et al. 2009; Sfeir et al. 2009). Fragile telomeres are also observed after treatment with low doses of the DNA polymerase $\alpha$ inhibitor aphidicolin, pointing to replication defects as their origin and highlighting their similarity to the aphidicolin-induced common fragile site (CFS) (Martinez et al. 2009; Sfeir et al. 2009). Indeed, one of the human CFSs (at 2q14) coincides with interstitial telomeric DNA and is induced by shRNA-mediated knockdown of TRF1 (Bosco and de Lange 2012). Thus, TRF1 prevents the fragile phenotype at both telomeres and interstitial telomeric DNA.

The telomeric replication stress induced upon TRF1 deletion results in the activation of the ATR kinase, as evidenced by the ATR-dependent appearance of $\gamma$-H2AX and 53BP1 at telomeres (Martinez et al. 2009; Sfeir et al. 2009). These telomere dysfunction-induced foci (TIFs) (Takai et al. 2003) only form in cells that have progressed through S phase without TRF1 (Sfeir et al. 2009), arguing that ATR activation is a consequence of the replication problems and not due to general telomere deprotection. Indeed, the protective functions of shelterin-mediated by TRF2, POT1a, and POT1b-appear intact in the absence of TRF1. For instance, TRF1 deletion does not unleash the ATM signaling and telomere fusions typical of TRF2 removal or induce endoreduplication and excessively long telomeric 3 ' overhangs, the insignia of telomeres lacking POT1a and POT1b (Sfeir et al. 2009). Furthermore, the replication dependence of ATR signaling in TRF1 knockout cells argues against a general impairment of POT1a function that would result in ATR activation before $S$ phase (Gong and de Lange 2010). Thus, while shelterin is a critical telomere end protection complex, the TRF1 subunit is largely dispensable for this function, instead being dedicated to the duplication of the telomeric DNA.

Lacking known enzymatic activities that could promote replication fork progression, TRF1 is assumed to execute its function by recruiting shelterin accessory factors. Candidate factors are the Bloom's syndrome BLM RecQ helicase and the RTEL1 (regulation of telomere elongation 1) helicase (Sfeir et al. 2009). These two helicases can dismantle G-G Hoogsteen base-paired structures such as the G quadruplexes (Sun et al. 1998; Mohaghegh et al. 2001; Huber et al. 2002; Ding et al. 2004; Vannier et al. 2012) that are readily formed by single-stranded TTAGGG repeats in vitro (for review, see Bryan and Baumann 2011). Upon inhibition of the BLM or
RTEL1 but not the WRN helicase, mouse cells show a fragile telomere phenotype, and as knockdown of either BLM or RTEL1 does not further exacerbate the phenotype of TRF1 deletion, they appear to act in the TRF1 pathway (Sfeir et al. 2009). In addition to BLM and RTEL1, Topoisomerase II $\alpha$ and Timeless have been implicated in the mechanism by which TRF1 guards against the fragile telomere phenotype (Leman et al. 2012; d'Alcontres et al. 2014).

Here we investigate the mechanism by which TRF1 navigates telomeric replication problems. We report that BLM was required to repress the fragile phenotype specifically in telomeres formed by lagging strand DNA synthesis (lagging end telomeres) but had no role at leading end telomeres. TRF1 bound directly to BLM, and this interaction was required to mediate the replication of lagging end telomeres, establishing BLM as a shelterin accessory factor (for review, see Diotti and Loayza 2011). BLM was not required for the repression of ATR signaling by TRF1 and played no detectable role in preventing the association of sister telomeres. Sister telomere associations are a prominent phenotype associated with TRF1 deletion; as they do not originate from classical nonhomologous end-joining (c-NHEJ), their molecular basis remains undefined (Sfeir et al. 2009). Sister telomere associations have also been observed at low frequency in other settings where ATR is activated at telomeres, including deletion of POT1a and POT1b (Hockemeyer et al. 2006). Activation of ATR signaling and the accompanying sister telomere associations were primarily prevented by the interaction of TRF1 with the TIN2/TPP1/POT1 branch of shelterin. We therefore propose that TRF1 uses TPP1/ POT1 heterodimers to prevent replication-dependent activation of the ATR kinase, most likely through the same RPA exclusion mechanism that blocks ATR activation at the telomere terminus.

\section{Results}

$B L M$ is epistatic with TRF1 and represses formation of fragile lagging end telomeres

Previous work showed that BLM shRNA knockdown does not exacerbate the fragile telomere phenotype induced by deletion of TRF1 (Sfeir et al. 2009). Together with the fragile telomere phenotype of BLM hypomorphic mouse embryonic fibroblasts (MEFs) (Luo et al. 2000), this finding led to the proposal that BLM acts downstream from TRF1 (Sfeir et al. 2009). To further test this notion, we generated SV40 large T (SV40-LT) immortalized conditional $\mathrm{BLM}^{\mathrm{F} / \mathrm{F}}$ MEFs (Chester et al. 2006), which result in BLM deficiency after introduction of Cre, and confirmed the presence of a significant level of fragile telomeres upon BLM deletion (Fig. 1A-C). Compared with deletion of TRF1, deletion of BLM induced fragile telomeres at a significantly lower frequency. Furthermore, the codeletion of BLM and TRF1 from doubleknockout MEFs did not increase the severity of the fragile telomere phenotype compared with that of TRF1 deletion alone (Fig. 1A-C). These data are consistent with the 


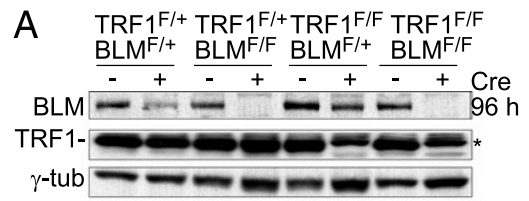

B
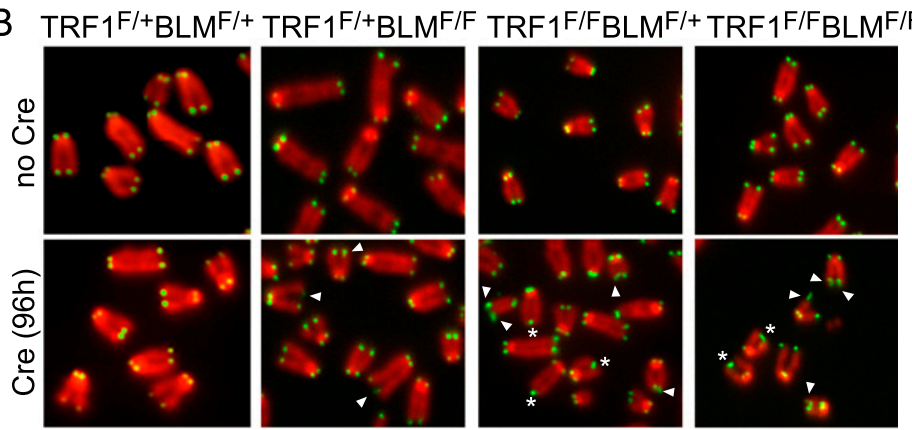

C

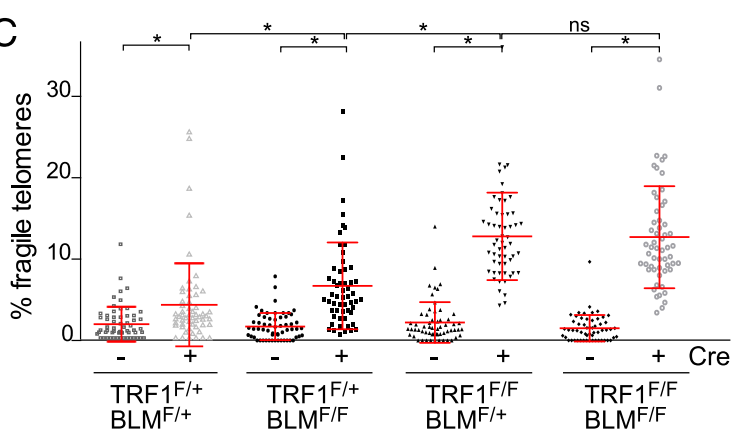

D

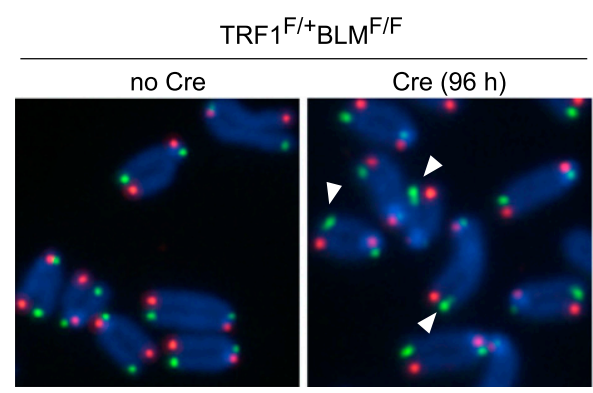

E

Leading-end telomeres

Lagging-end telomeres

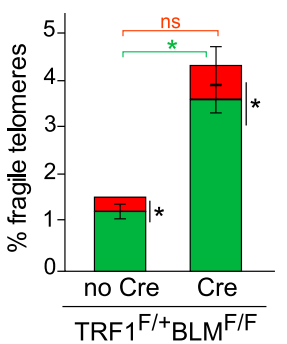

Figure 1. BLM cooperates with TRF1 to prevent fragile lagging end telomeres. (A) Cre-mediated deletion of TRF1 and BLM from MEFs of the indicated genotypes monitored by immunoblotting. $\left({ }^{\star}\right)$ Nonspecific band. (B) Metaphase telomeric FISH (green) showing fragile telomeres (arrows) and sister telomere associations (asterisks) in MEFs as in A. (Red) DNA DAPI stain. $(C)$ Quantification of fragile telomeres in cells shown in $B$. Fragile telomeres were scored in three experiments on $>2000$ long arm telomeres per experiment. Each symbol indicates the percentage of fragile telomeres in an analyzed metaphase. Error bars show SDs. Statistical significance $\left(\left[{ }^{\star}\right] P<0.05\right.$; [ns] not significant) from one-way ANOVA with Tukey's correction for multiple comparisons. (D) CO-FISH examples of lagging end fragile telomeres (arrows) in $\mathrm{TRF}^{\mathrm{F} /+} \mathrm{BLM}^{\mathrm{F} / \mathrm{F}}$ cells ( \pm Cre). (Green) Lagging end telomeres; (red) leading end telomeres; (blue) DAPI. (E) Quantification of leading end (red) and lagging end (green) fragile telomeres (as shown in $D$ ). Data are means of three independent experiments \pm SDs. More than 1500 long arm telomeres were scored per experiment. Statistics are as in $C$. proposal that BLM and TRF1 act in the same pathway. MEFs heterozygous for both BLM and TRF1 showed a slight elevation of the fragile telomere phenotype, perhaps pointing to a minor haploinsufficiency for TRF1 that only becomes apparent when BLM is also reduced.

As the fragile telomere phenotype induced by BLM deletion is less severe than that of TRF1 deficiency, we determined whether the role of BLM is limited to either leading or lagging end telomeres. Previously, chromosome orientation FISH (CO-FISH) showed that the fragile phenotype induced by TRF1 deletion was distributed equally between leading and lagging end telomeres (see Fig. 2, below; Sfeir et al. 2009). Although the weaker signals of CO-FISH make it more difficult to visualize telomere aberrations, BLM-deficient cells showed a clear fragile telomere phenotype when analyzed by this method.
Importantly, BLM loss resulted in a strong bias toward lagging end telomeres with regard to telomere fragility (Fig. 1D,E). We note that the (infrequent) fragile telomeres in cells with normal TRF1 levels are also biased toward lagging end telomeres, suggesting that "spontaneous" telomere replication problems primarily occur during lagging strand DNA synthesis.

\section{Generation of an allele of TRF1 deficient in BLM binding}

We next sought to determine whether the epistasis noted above reflected a physical association of TRF1 and BLM. The helicase domain of BLM was previously reported to interact with TRF1 in vitro (Lillard-Wetherell et al. 2004), but the TRF1 region involved in this binding was not 

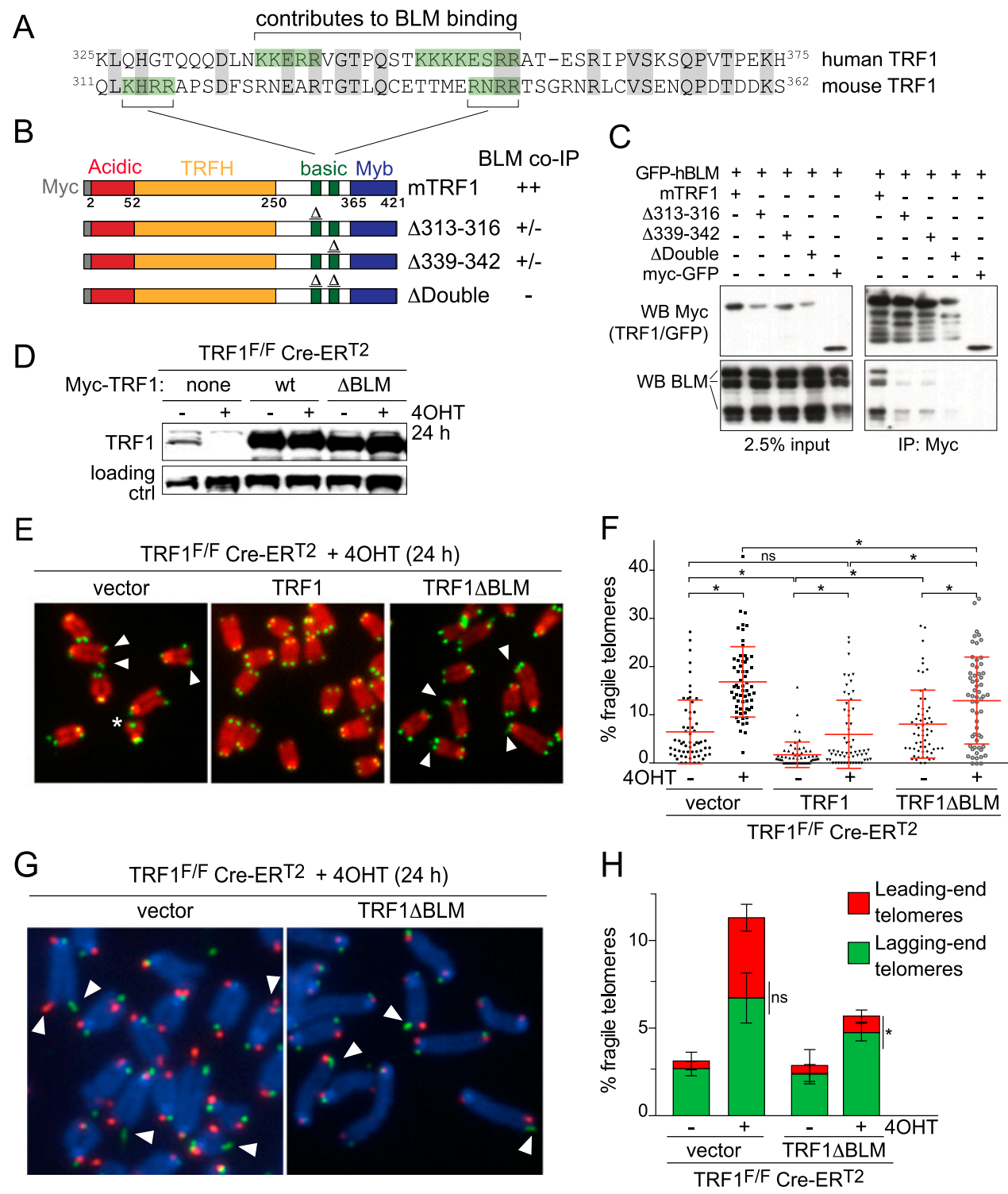

Figure 2. TRF1 binds BLM to prevent fragile lagging end telomeres. (A) Alignment of human and mouse TRF1 hinge domain sequences. (Green box) Basic patches implicated in BLM binding. (B) Schematic of the mouse TRF1 alleles used in coimmunoprecipitations (co-IPs) with human BLM. Deletions of the individual basic patches (as shown in $A$ ) are indicated by $\Delta$. (C) Anti-Myc co-IPs of human BLM with mouse TRF1 alleles shown in $B$ from cotransfected 293T cells. Immunoblots were probed with anti-Myc (top) and anti-BLM (bottom) antibodies. BLM is partially degraded in these experiments. $(D)$ Immunoblot for Myc-TRF1 and Myc-TRF1 $\Delta B L M$ $\left(\mathrm{TRF} 1 \Delta\right.$ Double in $B$ and $C$ ) in $\mathrm{TRF} 1^{\mathrm{F} / \mathrm{F}} \mathrm{Cre}-\mathrm{ER}^{\mathrm{T} 2}$ cells with or without 4-hydroxytamoxifen $(4 \mathrm{OHT})$ treatment. $(E)$ Examples of metaphase TTAGGG FISH (green) images of $4 \mathrm{OHT}$-treated $\mathrm{TRF}{ }^{\mathrm{F} / \mathrm{F}} \mathrm{Cre}-\mathrm{ER}^{\mathrm{T} 2}$ MEFs complemented with the indicated Myc-TRF1 constructs. (Arrows) Fragile telomeres; (red) DAPI. (F) Frequency of fragile telomeres (plotted for individual metaphases) in TRF1 ${ }^{\mathrm{F} / \mathrm{F}} \mathrm{Cre}$ $\mathrm{ER}^{\mathrm{T} 2}$ cells as in $E$. More than 1500 long arm telomeres were scored in each of four independent experiments. Error bars represent SDs. Statistics are as in Figure 1C. $(G)$ CO-FISH showing leading end (red) and lagging end (green) fragile telomeres in $4 \mathrm{OHT}$-treated TRF1 $1^{\mathrm{F} / \mathrm{F}} \mathrm{Cre}$ $\mathrm{ER}^{\mathrm{T} 2}$ cells with or without TRF1 $\triangle$ BLM. (Blue) DAPI. $(H)$ Quantification of leading and lagging end fragile telomeres in TRF1 ${ }^{\mathrm{F} / \mathrm{F}} \mathrm{Cre}-\mathrm{ER}^{\mathrm{T} 2} \mathrm{Cell}^{\mathrm{s}}$ as in $G$. Data are means \pm SDs of three independent experiments. Statistics are as in Figure 1C.

identified. To this end, we first analyzed the interaction of GFP-tagged human BLM (GFP-hBLM) with Myc-tagged human TRF1 alleles (Supplemental Fig. 1A,B). Full-length TRF1 and TRF1 lacking the C-terminal Myb domain interacted with BLM, whereas deletion of the hinge region or the acidic $\mathrm{N}$ terminus reduced the interaction. Due to its lower expression, the lack of interaction of TRF1 $\Delta$ Ac with BLM interaction is difficult to interpret. Thus, the
TRF1 hinge domain and possibly the acidic $\mathrm{N}$ terminus contributed to BLM binding.

As the acidic $\mathrm{N}$ terminus of TRF1 is not required for repression of the fragile telomere phenotype (Sfeir et al. 2009), we focused on the contribution of the hinge region to the TRF1-BLM interaction. Deletion of amino acids 317-374 abolished the interaction with BLM, whereas deletion of amino acids 285-320 did not (Supplemental 
Fig. $1 \mathrm{C}, \mathrm{D}$ ). Further deletion analysis pointed to a 22 -aminoacid stretch (amino acids 337-357) containing two basic patches as important for the interaction with BLM (Supplemental Fig. 1C-E). Despite the poor conservation of the hinge domain $(38 \%$ amino acid identity between humans and mice) (Broccoli et al. 1997), two basic patches are also present in mouse TRF1 (Fig. 2A). Deletion of either of the basic patches diminished the interaction of mouse TRF1 with human BLM, and the interaction was entirely abolished when both were deleted (Fig. 2B,C). Poor expression of mouse BLM in 293T cells thwarted attempts to verify the interactions between mouse TRF1 and BLM. However, since human TRF1 binds to the helicase domain (LillardWetherell et al. 2004), which is nearly identical (93\% amino acid identity) in mouse and human BLM, it is likely that the murine TRF1-BLM interaction interface is conserved. We refer to the mouse TRF1 allele lacking both BLM-binding motifs as TRF1 $\triangle B L M$.

\section{TRF1ABLM is defective in repressing the fragile} telomere phenotype

To determine the functional significance of the TRF1-BLM interaction, tamoxifen-inducible TRF1 knockout MEFs (SV40-LT immortalized TRF1 ${ }^{\mathrm{F} / \mathrm{F}} \mathrm{Cre}-\mathrm{ER}^{\mathrm{T} 2}$ ) were complemented with TRF1 $\triangle B$ BM or full-length TRF1. The two versions of TRF1 were overexpressed to the same level (Fig. 2D), and although both showed the expected cell-tocell variation in immunofluorescence (IF) intensities (Supplemental Fig. 2A), their telomeric localization patterns were indistinguishable (Supplemental Fig. 2B,C). Chromatin immunoprecipitation (ChIP) revealed that both proteins compensated for the loss of TRF1 from telomeric DNA that is observed upon deletion of the endogenous TRF1 (Supplemental Fig. 2D,E). Exogenous Myc-TRF1 resulted in excess TRF1 loading on telomeres compared with the endogenous TRF1, which was not observed with TRF1 $\triangle$ BLM (Supplemental Fig. 2D,E). Since we were unable to detect BLM at mouse telomeres by IF, it could not be established whether the recruitment of BLM to telomeres was abolished in cells expressing TRF1 $\triangle \mathrm{BLM}$.

TRF1 $\triangle$ BLM showed a significant defect in the repression of the fragile telomere phenotype (Fig. 2E,F). The increase in the frequency of fragile telomeres in TRF1 $\triangle B L M$-expressing cells after treatment with Cre was similar to that caused by BLM deletion (Fig. 1). This result is consistent with BLM repressing the fragile telomere phenotype primarily through binding to TRF1. We note that the frequency of fragile telomeres in the TRF1 $\triangle B L M$-complemented cells is higher than in the BLM-deficient cells. This is likely due to the higher basal level of fragile telomeres in the $\mathrm{TRF}^{\mathrm{F} / \mathrm{F}} \mathrm{Cre}-$ ER $^{\mathrm{T2}}$ MEFs.

Consistent with the results with BLM-deficient cells, cells complemented with the TRF1 $\triangle B L M$ allele showed a strand bias in their fragile telomere phenotype, with most of the fragile telomeres resulting from lagging strand DNA synthesis (Fig. 2G,H). In contrast, TRF1deficient cells lacking any form of TRF1 did not show this bias (Fig. 2G,H), confirming previous findings (Sfeir et al. 2009).
Repression of ATR signaling and sister telomere associations by TRF1ABLM

Deletion of BLM did not induce a significant telomere damage signal (Fig. 3A,B; Supplemental Fig. 3). Consistent with this finding, TRF1 $\triangle B L M$ repressed the telomeric DNA damage signaling that is unleashed upon loss of the endogenous TRF1 (Fig. 3C,D). Similarly, the sister telomere associations that arise when TRF1 is deleted were not observed in cells complemented with TRF1 $\triangle \mathrm{BLM}$ or in BLM-deficient cells (Fig. 3E,F). Thus, the TRF1 BBLM allele showed a separation-of-function phenotype, being partially deficient in preventing the fragile telomere phenotype but proficient in other functions of TRF1.

\section{ATR activation and sister telomere associations are due to loss of TRF1-bound TIN2}

We next addressed how ATR signaling is managed by TRF1. TRF1 can repress ATR in a BLM-independent manner, as shown by the lack of ATR signaling at telomeres lacking BLM, despite their replication problems. This repression of ATR could involve the ability of TRF1 to bind to TIN2, thus potentially positioning TPP1/POT1 heterodimers at sites of fork replication stalling. When TRF1 is deleted, the accumulation of TIN2 at telomeres is diminished. However, this loss of TIN2 does not result in complete removal of TPP1/ POT1 from telomeres, as there is no evidence for two phenotypes associated with complete loss of POTla or POT1b: endoreduplication and deregulation of the $3^{\prime}$ overhang, respectively (Table 1; Sfeir et al. 2009). In contrast, when TIN2 is deleted, the phenotypes of POT1a/b deletion are observed to the same extent as in POTla/b doubleknockout cells (Table 1; Takai et al. 2011). Thus, the residual TRF2-tethered TIN2 in the TRF1-deficient cells is sufficient to support most of the protective functions of POT1a and POT1b. Similarly, when TIN2-deficient cells are complemented with a mutant of TIN2 that binds TRF2 but not TRF1, there is modest activation of the ATR kinase at telomeres in the absence of an overall POTla/b loss phenotype (Table 1; Frescas and de Lange 2014a). This indicates that POTla and POT1b are capable of protecting the telomere termini when the TRF1-TIN2 connection is severed. Therefore, the ATR signaling observed when TIN2 is not connected to TRF1 (Frescas and de Lange 2014a) might well be due to replication stress rather than exposure of the telomeric $3^{\prime}$ overhang.

To test whether the ATR signaling caused by deletion of TRF1 is due to loss of TIN2, we used the TIN2 ${ }^{\mathrm{RCT}}$ allele (Frescas and de Lange 2014a). TIN2 ${ }^{\mathrm{RCT}}$ is a TIN2 fusion protein that contains the RCT TRF2-binding domain of Rap1, improving its accumulation at telomeres in the absence of the TRF1-TIN2 link (Frescas and de Lange 2014a). To determine whether a TRF2-tethered TIN2 had the ability to repress ATR signaling when TRF1 is deleted, TIN2 with or without the RCT domain (Flag-HA ${ }_{2}-$ TIN2 ${ }^{\text {RCT }}$ and Flag-HA - -TIN2, respectively) was expressed in $\mathrm{TRF}^{\mathrm{F} / \mathrm{F}}$ cells (Fig. 4A,B) and examined for their localization at telomeres after deletion of TRF1. As expected from prior work (Frescas and de Lange 2014a), minimal telomeric accumulation was observed for either the endog- 
A

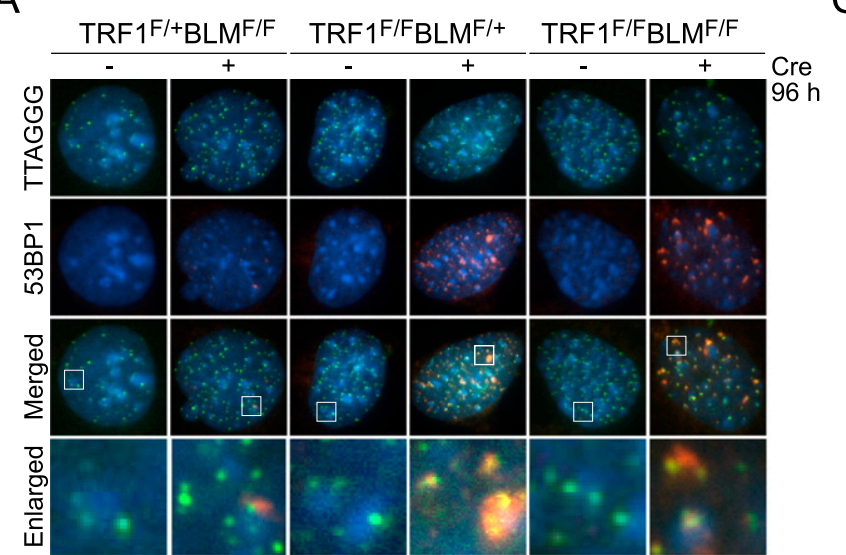

C

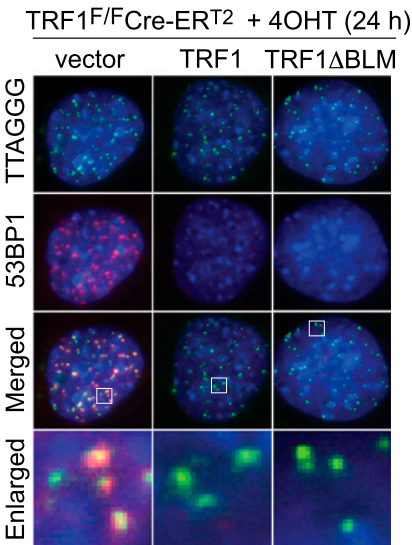

B

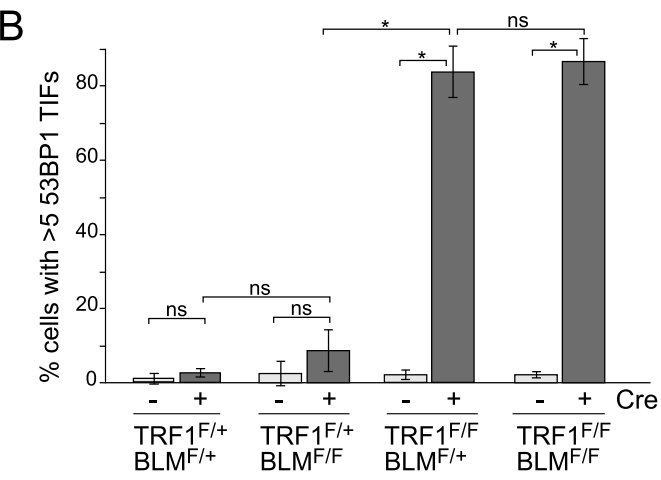

E

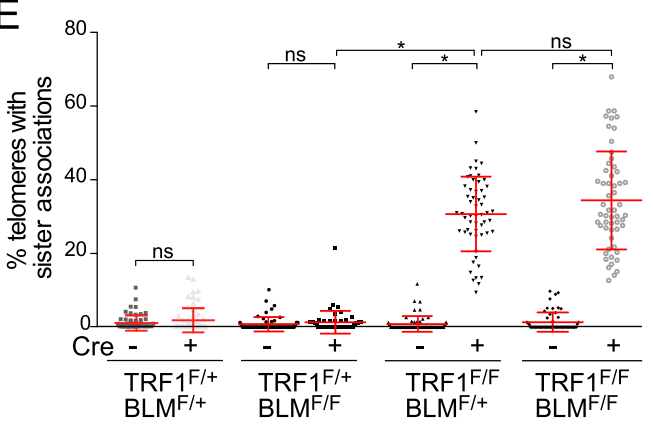

D

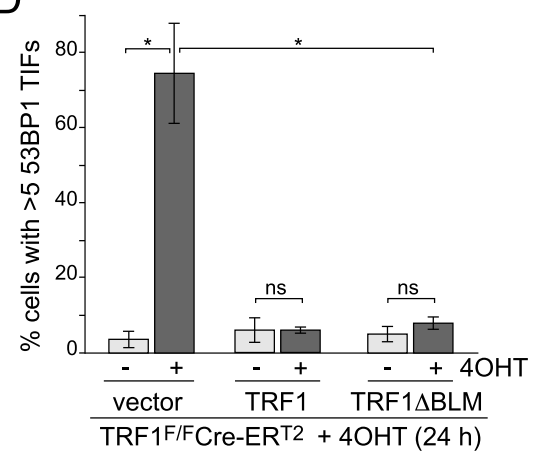

F

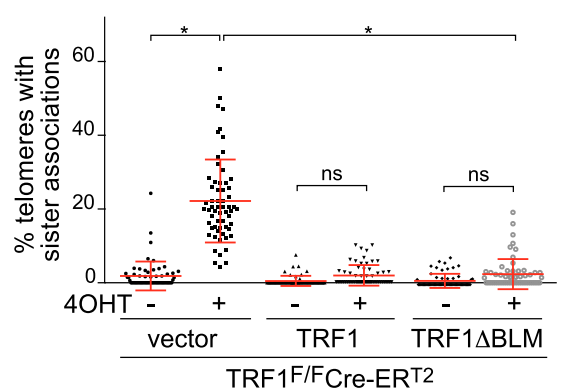

Figure 3. BLM-independent functions of TRF1. (A) TIF assay on the indicated cells with and without Cre. IF for 53BP1 (red) combined with telomeric TTAGGG FISH (green). (Blue) DAPI. (B) Percentages of nuclei (cells as in $A$ ) showing more than five 53BP1 TIFs. Data are means from three independent experiments \pm SDs. At least 100 cells were scored in each experiment. (C) IF-FISH as in $A$ on 4 OHT-treated $\mathrm{TRF}^{\mathrm{F} / \mathrm{F}}$ Cre-ER ${ }^{\mathrm{T} 2}$ cells with full-length TRF1 or TRF1 $\Delta \mathrm{BLM}$. $(D)$ Quantification of TIF-positive (more than five) nuclei as in $C$. Data in $B$ and $D$ are means of three independent experiments \pm SDs $(n \geq 100$ nuclei per experiment). (E) Percentages of sister telomere associations (illustrated in Fig. 1B) in the indicated cells with or without Cre. (F) Quantification of sister telomere associations in TRF1 ${ }^{\mathrm{F} / \mathrm{F}} \mathrm{Cre}-\mathrm{ER}^{\mathrm{T} 2}$ cells transduced with the indicated constructs. Data in $E$ and $F$ are plotted as percentages of long arm sister telomere associations in each metaphase analyzed in at least three independent experiments ( $>2000$ telomeres per experiment). Statistics are as in Figure $1 \mathrm{C}$.

enous or exogenous TIN2 when TRF1 was deleted, whereas $\mathrm{TIN} 2^{\mathrm{RCT}}$ accumulated at telomeres in a manner that was independent of TRF1 (Supplemental Fig. 4A,B).

Notably, TIN2 ${ }^{\text {RCT }}$ repressed most of the ATR signaling at telomeres in cells from which TRF1 was deleted (Fig. 4C,D) despite the occurrence of fragile telomeres (Supplemental Fig. 4C). In contrast, the wild-type TIN2 failed to decrease the 53BP1 TIFs after TRF1 deletion (Fig. 4C,D). In fact, ATR signaling was slightly increased by overexpression of TIN2, perhaps because the overexpression leads to nucleoplasmic TIN2 (see Supplemental Fig. 4A) that can titrate TPP1/
POT1 away from the telomeres. A removal of TPP1/POT1 from telomeres also explains the increase in the $3^{\prime}$ overhang signal in TRF1-deficient cells overexpressing TIN2 (Supplemental Fig. 4D). Regardless of the effects of TIN2 overexpression, the data obtained with $\mathrm{TIN} 2^{\mathrm{RCT}}$ are consistent with the proposal that TRF1 represses ATR signaling at stalled replication forks by recruiting TIN2/TPP1/POT1.

The increased loading of TIN2 on the telomeres afforded by the TIN2 ${ }^{\mathrm{RCT}}$ allele also diminished the association of sister telomeres after loss of TRF1 (Fig. 4E,F). Repression of sister telomere associations is therefore another function 
Table 1. Summary of relevant TRF1, BLM, TIN2, TPP1, POT1a, and POT1b deletion phenotypes

\begin{tabular}{|c|c|c|c|c|c|c|}
\hline $\begin{array}{l}\Delta \text { Genes + complementing } \\
\text { gene }\end{array}$ & $\begin{array}{c}\text { ATR } \\
\text { activation }^{\mathrm{b}}\end{array}$ & $\begin{array}{c}\text { Sister } \\
\text { telomere } \\
\text { association }\end{array}$ & $\begin{array}{l}\text { Increase in } \\
\text { fragile } \\
\text { telomeres }\end{array}$ & $\begin{array}{c}\text { Increase in } \\
\text { overhang } \\
\text { signal }\end{array}$ & $\begin{array}{l}\text { Endore- } \\
\text { duplication }\end{array}$ & References \\
\hline$\Delta \mathrm{TRF} 1$ & $75 \%-90 \%$ & $25 \%-30 \%$ & $8 \%-12 \%$ & $<1.5$-fold & - & This study \\
\hline$\Delta \mathrm{TRF} 1+\mathrm{TRF} 1 \Delta B L M$ & - & - & $5 \%$ (lagging) & $<1.5$-fold & - & This study \\
\hline$\Delta \mathrm{BLM}$ & - & - & $5 \%$ (lagging) & $<1.5$-fold & - & This study \\
\hline$\Delta \mathrm{TRF} 1 / \Delta \mathrm{BLM}$ & $80 \%$ & $35 \%$ & $10 \%$ & $<1.5$-fold & - & This study \\
\hline$\Delta \mathrm{TRF} 1+\mathrm{TIN} 2 R C T$ & $5 \%$ & $6 \%-8 \%$ & $13 \%$ & $<1.5$-fold & - & This study \\
\hline$\Delta \mathrm{TRF} 1 / \Delta \mathrm{TPP} 1^{\mathrm{a}}$ & $90 \%$ & $22 \%$ & $9 \%$ & na & ++ & This study \\
\hline$\Delta \mathrm{TRF} 1 / \Delta \mathrm{TPP} 1^{\mathrm{a}}+\mathrm{TIN} 2 R C T$ & $90 \%$ & $25 \%$ & $9 \%$ & na & nd & This study \\
\hline$\Delta \mathrm{POT} 1 \mathrm{a} / \Delta \mathrm{POT} 1 \mathrm{~b}$ & $80 \%$ & $3 \%$ & - & $\begin{array}{l}\text { Twofold to } \\
\text { threefold }\end{array}$ & ++ & Hockemeyer et al. 2006 \\
\hline$\Delta$ POT1a & $30 \%$ & $1.5 \%$ & - & $<1.5$-fold & ++ & Hockemeyer et al. 2006 \\
\hline$\Delta \mathrm{POT} 1 \mathrm{~b}$ & - & - & - & $\begin{array}{l}\text { Twofold to } \\
\text { threefold }\end{array}$ & - & Hockemeyer et al. 2006 \\
\hline$\Delta \mathrm{TPP} 1$ & $80 \%$ & $4 \%$ & - & $\begin{array}{l}\text { Twofold to } \\
\text { threefold }\end{array}$ & ++ & Kibe et al. 2010 \\
\hline$\Delta \mathrm{TIN} 2$ & $80 \%$ & $7 \%$ & - & $\begin{array}{l}\text { Twofold to } \\
\text { threefold }\end{array}$ & ++ & Takai et al. 2011 \\
\hline$\Delta \mathrm{TIN} 2+\mathrm{TIN} 2 \Delta \mathrm{TPP} 1$ & $80 \%$ & $4 \%$ & - & Twofold & nd & Frescas and de Lange 2014a \\
\hline$\Delta \mathrm{TIN} 2+\mathrm{TIN} 2 \Delta \mathrm{TRF} 1$ & $60 \%{ }^{d}$ & $4 \%$ & - & $<1.5$-fold & - & Frescas and de Lange $2014 \mathrm{~b}$ \\
\hline
\end{tabular}

(-) Not detected; (nd) not determined; (na) not applicable in absence of 53BP1.

${ }^{\mathrm{a} C}$ Cells are $53 \mathrm{BP} 1^{-/-}$.

${ }^{\mathrm{b}}$ Percent of cells with more than five TIFs.

${ }^{\mathrm{c}}$ Compared with untreated MEF line.

${ }^{\mathrm{d}}$ TIF-positive cells have fewer TIFs per nucleus compared with $\Delta$ TIN2.

that likely involves TRF1-mediated recruitment of the TIN2/TPP1/POT1 subunits of shelterin.

The telomeres in cells expressing $\mathrm{TIN} 2^{\mathrm{RCT}}$ contain a reduced amount of Rap1 (Frescas and de Lange 2014a), presumably because TIN2 ${ }^{\text {RCT }}$ competes with Rap1 for TRF2 binding. We therefore performed control experiments to determine whether the effects of $\mathrm{TIN} 2^{\mathrm{RCT}}$ could be attributed to the reduction of Rap1 at telomeres. To this end, SV40-LT immortalized TRF1 ${ }^{\mathrm{F} / \mathrm{F}} \mathrm{Rap}^{\mathrm{F} / \mathrm{F}}$ MEFs were generated, infected with the $\mathrm{TIN} 2^{\mathrm{RCT}}$ retrovirus or the empty vector, and treated with Cre (Supplemental Fig. 5A). The results showed that the absence of Rap1 did not alter the effect of TIN2 ${ }^{\text {RCT }}$ on the TIFs, sister telomere associations, and fragile telomeres induced by deletion of TRF1 (Supplemental Fig. 5B-F). We therefore conclude that the reduction of the ATR signaling and sister telomere associations in TRF1-deficient cells enforced by TIN $2^{\mathrm{RCT}}$ is not due to a loss of Rap1 from telomeres.

We note that the combined absence of Rapl and TRF1 resulted in a mild chromosome-type telomere fusion phenotype (Supplemental Fig. 5F). Possibly, TRF2 loading on telomeres in this setting is diminished due to a combined effect of the absence of Rapl and the lack of the TRF2-TIN2-TRF1 connection. TIN2 ${ }^{\text {RCT }}$ had no effect on these telomere fusions.

\section{Repression of sister telomere associations involves TPP1}

To confirm that the $\mathrm{TIN} 2^{\mathrm{RCT}}$-mediated repression of sister telomere associations in TRF1-deficient cells required the function of the TPP1/POT1 heterodimers, we generated SV40-LT immortalized TRF $1^{\mathrm{F} / \mathrm{F}} 53 \mathrm{BP} 1^{-/-}$and $\mathrm{TPP}^{\mathrm{F} / \mathrm{F}} \mathrm{TRF} 1^{\mathrm{F} / \mathrm{F}} 53 \mathrm{BP} 1^{-/-}$MEFs that expressed TIN2 ${ }^{\mathrm{RCT}}$ (Fig. 5A). The 53BP1-deficient background was used to avoid the confounding effects of NHEJ-mediated telomere fusions, which are sporadic in the absence of 53BP1 (see Fig. 5F, below).

As expected, in TPP1 $1^{\mathrm{F} / \mathrm{F}} \mathrm{TRF} 1^{\mathrm{F} / \mathrm{F}} 53 \mathrm{BP} 1^{-/-}$cells, TIN2 ${ }^{\mathrm{RCT}}$ failed to suppress DNA damage signaling at telomeres after Cre treatment, whereas it again diminished the ATR signaling after TRF1 deletion from TPP1-proficient cells (Fig. 5B,C). The interpretation of the ATR signaling in TPP1/TRF1 double-knockout cells expressing $\mathrm{TIN} 2^{\mathrm{RCT}}$ is confounded by the pervasive replication-independent ATR signaling due to the absence of POT1 (Gong and de Lange 2010) that will mask TIN2 $2^{\mathrm{RCT}}$-induced changes in the ATR signaling induced by TRF1 loss.

In contrast, sister telomere associations occur sporadically in TPP1-deficient cells (see Table 1; Hockemeyer et al. 2006; Kibe et al. 2010) such that TPP1 deletion should not mask the effects of TIN2 $2^{\mathrm{RCT}}$ on this phenotype. As expected, $\mathrm{TIN} 2^{\mathrm{RCT}}$ diminished the frequency of sister telomere associations when TRF1 was deleted from TPP1-proficient cells, whereas it again had no effect on the fragile telomere phenotype (Fig. 5D-F). In contrast, TIN2 ${ }^{\mathrm{RCT}}$ did not reduce the sister telomere association (or the fragile telomere phenotype) after simultaneous deletion of TRF1 and TPP1 (Fig. 5D-F). Thus, we conclude that the ability of TIN2 ${ }^{\text {RCT }}$ to repress the sister telomere associations upon deletion of TRF1 is negated in the absence of TPP1, consistent with TRF1 using the TIN2/TPP1/POT1 part of shelterin to avoid formation of these aberrant structures.

\section{Discussion}

The role of BLM at telomeres

Based on the data presented here, we propose that TRF1 interacts with the BLM helicase to repress the fragile 
A

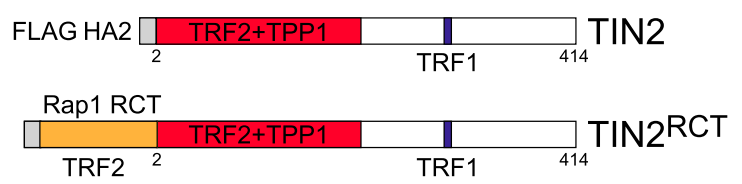

C

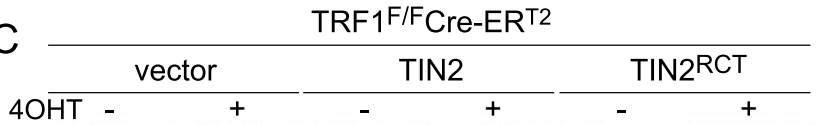

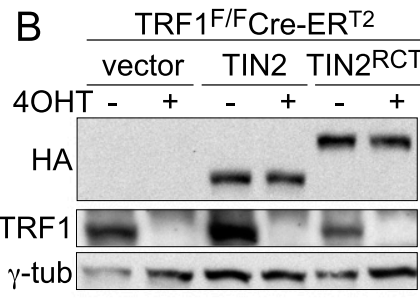

D

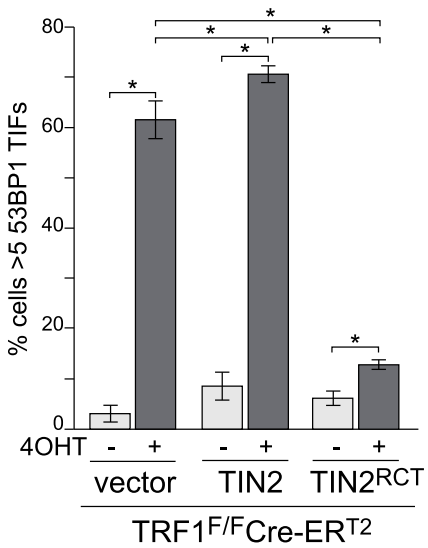

E TRF1F/FCre-ERT2

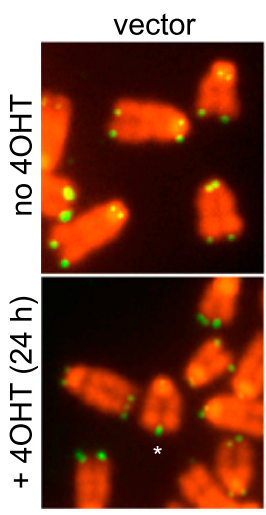
TIN2 TIN2RCT

$\mathrm{F}$
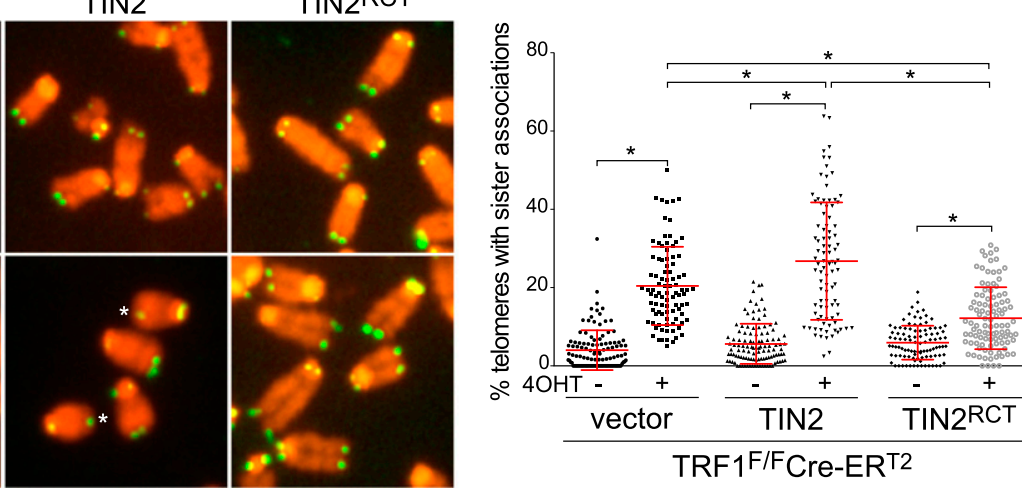

Figure 4. Tethering of TIN2 to TRF2 represses TIFs and sister telomere associations upon TRF1 deletion. $(A)$ Schematic of Flag-HA 2 -TIN2 and Flag-HA ${ }_{2}$-TIN2 ${ }^{\mathrm{RCT}}$ with TRF1-, TPP1-, and TRF2-binding sites shown. $(B)$ Immunoblotting for TIN2 and TIN2 ${ }^{\mathrm{RCT}}$ in TRF1 ${ }^{\mathrm{F} / \mathrm{F}} \mathrm{Cre}-\mathrm{ER}^{\mathrm{T} 2}$ cells \pm 4OHT. $(C)$ TIF analysis (as in Fig. $3 \mathrm{~A}$ ) on the TRF1 ${ }^{\mathrm{F} / \mathrm{F}} \mathrm{Cre}^{-\mathrm{ER}^{\mathrm{T} 2}}$ cells shown in $B .(D)$ Quantification of cells with more than five 53BP1 TIFs per nucleus as shown in C. See Figure 3B. (E) Sister telomere associations (asterisks) detected with telomeric FISH (green) in the cells described in $B$. (Red) DAPI. $(F)$ Percentages of sister telomere associations (as in $E$ ) in each analyzed metaphase. Scoring and statistics are as in Figures $3 \mathrm{E}$ and $1 \mathrm{C}$, respectively.

phenotype of telomeres that have been generated by lagging strand replication of telomeric DNA (Fig. 6). BLM is proposed to act by unwinding G quadruplexes or other secondary G-G base-paired structures, which can be formed in the TTAGGG repeat template for lagging strand telomeric DNA synthesis. In the absence of BLM, persistent $G$ quadruplexes are proposed to interrupt lagging strand DNA synthesis. The resulting discontinuity in lagging strand DNA synthesis is proposed to leave singlestranded TTAGGG repeat gaps, explaining the broken or partially uncondensed fragile appearance of the lagging end telomeres in BLM-deficient cells (Fig. 6). This proposal is consistent with the induction of a fragile telomere pheno- type by G4-stabilizing compounds (Rizzo et al. 2009; Vannier et al. 2012), although it is not known whether these compounds have a lagging end-specific effect.

In addition to unwinding G quadruplexes, BLM can mediate several reactions that could re-establish replication once a lesion is removed and thus contribute to the repression of the fragile telomere phenotype (van Brabant et al. 2000; Wu and Hickson 2003; Bachrati et al. 2006; Machwe et al. 2006, 2011; Ralf et al. 2006; Nimonkar et al. 2008, 2011). However, those activities of BLM are expected to affect both leading and lagging end telomeres. For this reason, we prefer the explanation that TRF1bound BLM primarily functions to resolve G-G base-paired 
A

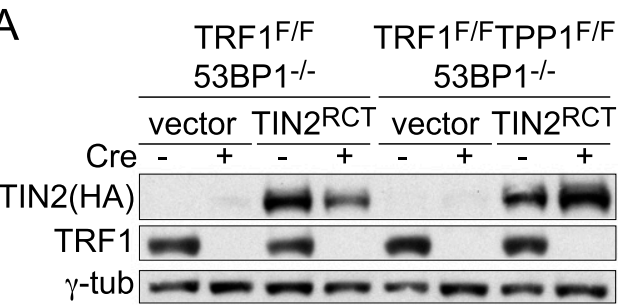

C

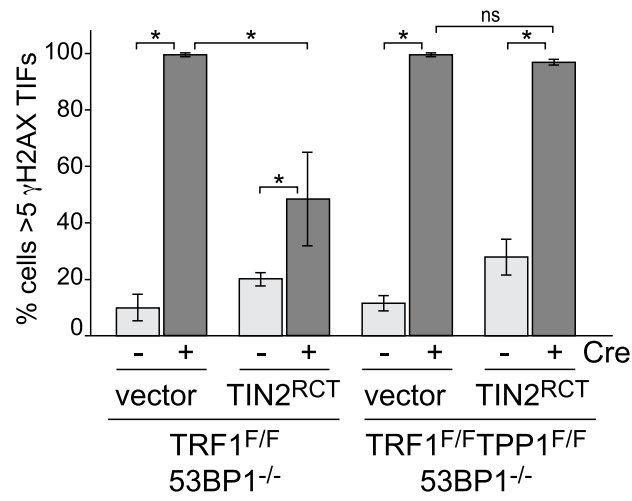

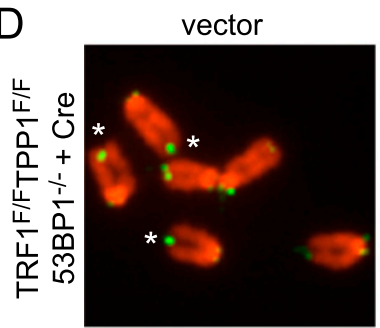
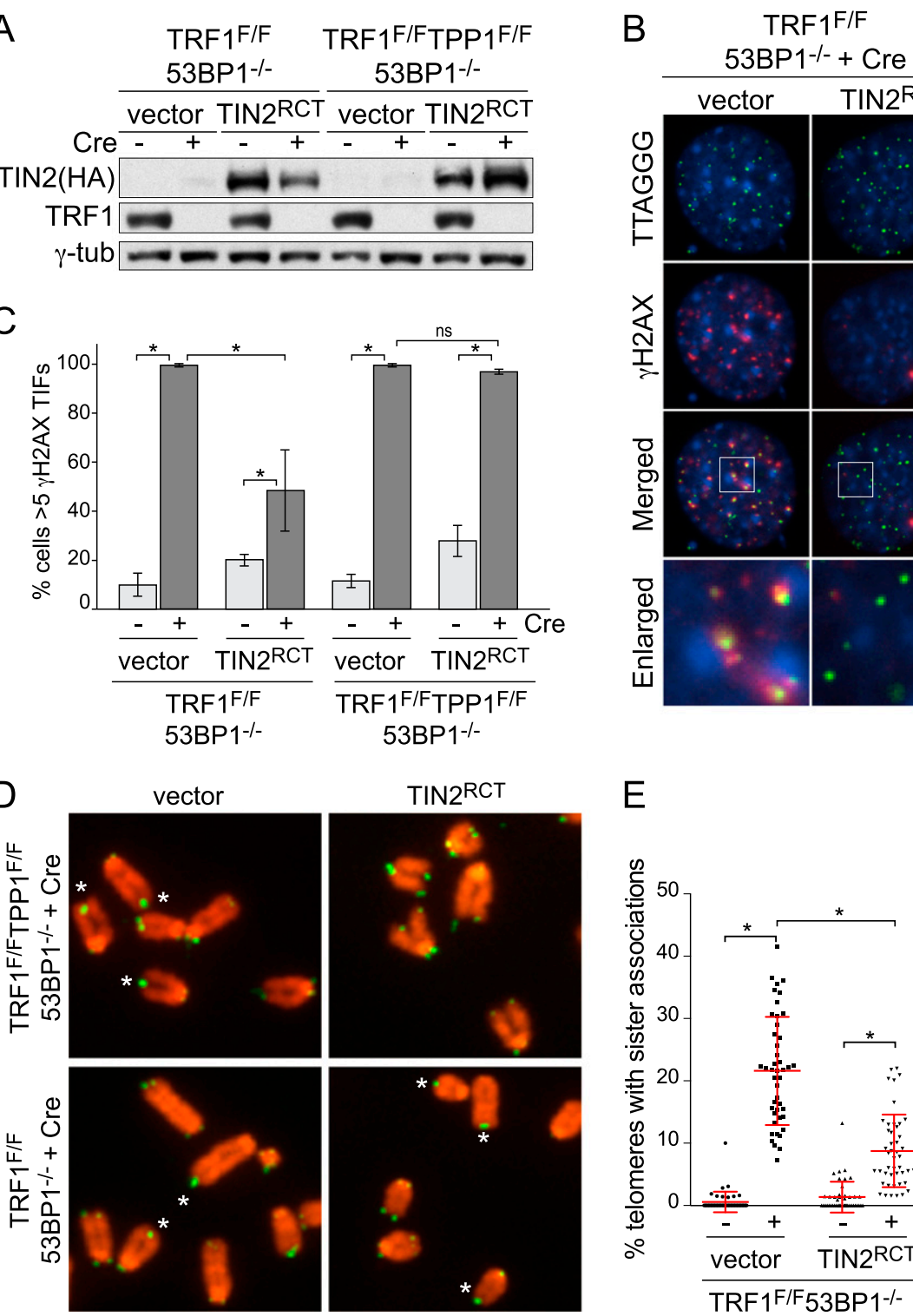

TRF1F/FTPP1F/F

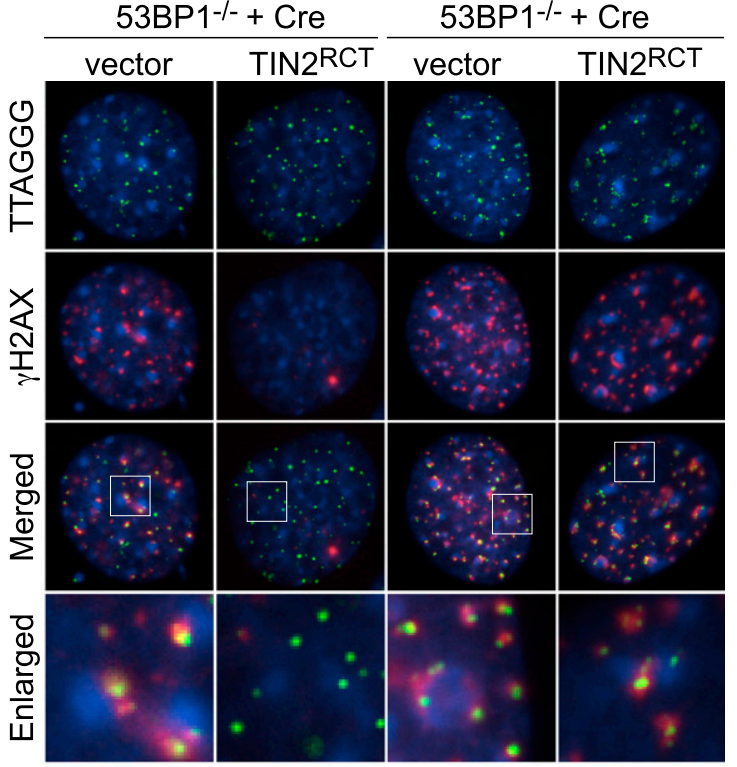

$E$

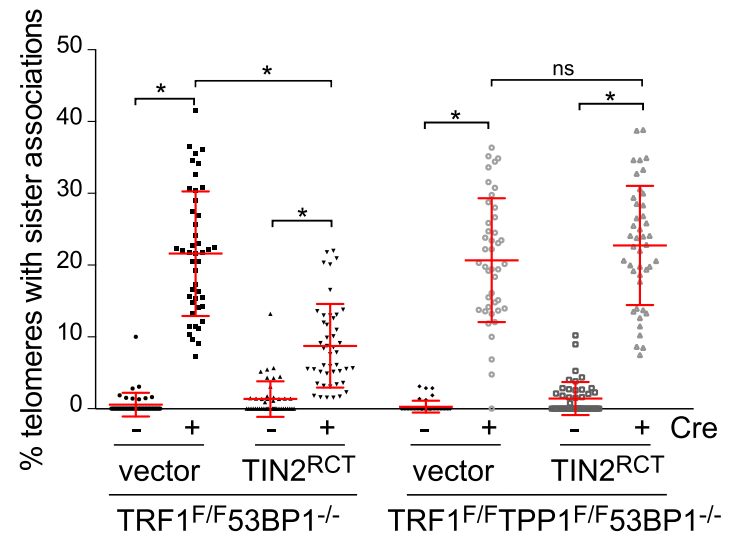

$\mathrm{F}$

\begin{tabular}{|c|c|c|c|c|}
\hline & \multicolumn{2}{|c|}{$\%$ fragile telomeres } & \multicolumn{2}{|c|}{$\begin{array}{l}\% \text { non-sister telomere } \\
\text { fusions/associations }\end{array}$} \\
\hline & no Cre & Cre & no Cre & Cre \\
\hline TRF1F/F 53BP1-/- + vector & $4 \pm 1$ & $16 \pm 1$ & $<0.3$ & $2 \pm 0.8$ \\
\hline TRF1F/F 53BP1-/- + TIN2RCT & $10 \pm 3$ & $21 \pm 6$ & $<0.3$ & $1 \pm 0.3$ \\
\hline TRF1F/F TPP1F/F 53BP1-/- + vector & $4 \pm 2$ & $13 \pm 0.6$ & $<0.3$ & $7 \pm 3$ \\
\hline TRF1F/F TPP1F/F53BP1-/- +TIN2RCT & $9 \pm 2$ & $13 \pm 3$ & $<0.3$ & $11 \pm 3$ \\
\hline
\end{tabular}

Figure 5. Repression of sister telomere associations requires TRF1 and TPP1. (A) Immunoblotting for TIN2 $2^{\mathrm{RCT}}$ in $\mathrm{TRF1}^{\mathrm{F} / \mathrm{F}} 53 \mathrm{BP} 1^{-/-}$ and $\mathrm{TRF}^{\mathrm{F} / \mathrm{F}} \mathrm{TPP}^{\mathrm{F} / \mathrm{F}} 53 \mathrm{BP} 1^{-/-}$cells \pm Cre. $(B)$ IF for $\gamma \mathrm{H} 2 \mathrm{AX}$ (red) combined with telomeric FISH (green) in cells as in $A$. (Blue) DAPI. $(C)$ Percentage of cells with more than five $\gamma$-H2AX TIFs per nucleus as shown in B. Data are means of three independent experiments \pm SDs (>100 nuclei per experiment). (D) Sister telomere associations (asterisks) detected as in Figure 4E in the cells described in $A$. (Red) DAPI. (E) Percentages of sister telomere associations (as in $D$ ) in each analyzed metaphase. Scoring and statistics are as in Figures $3 \mathrm{E}$ and $1 \mathrm{C}$, respectively. $(F)$ Summary of telomere fragility and nonsister telomere fusions/associations in $\mathrm{TRF1}^{\mathrm{F} / \mathrm{F}} 53 \mathrm{BP} 1^{-/-}$and $\mathrm{TRF1}^{\mathrm{F} / \mathrm{F}} \mathrm{TPP}^{\mathrm{F} / \mathrm{F}} 53 \mathrm{BP1}^{-/-}$cells. Means of three independent experiments \pm SDs. Fragile telomeres were scored on $>1500$ long arm telomeres per experiment. 


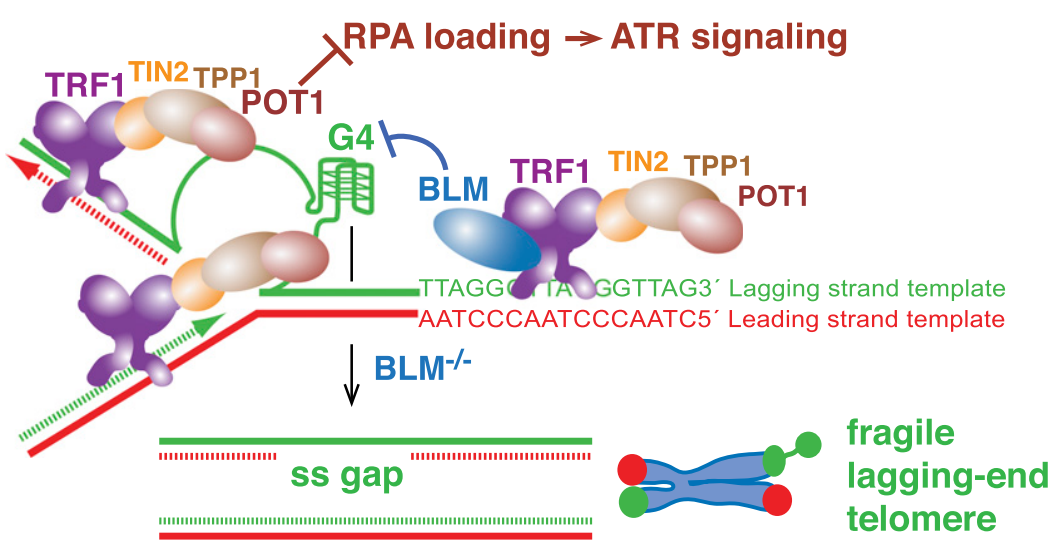

Figure 6. Proposed mechanism for TRF1-mediated telomere protection during telomere replication. TRF1 recruits the BLM helicase to dismantle $G$ quadruplexes in the lagging strand template, thereby preventing replication fork stalling and persistence of single-stranded (ss) gaps that lead to the formation of the fragile telomere phenotype specifically in lagging end telomeres. How TRF1 prevents fragile leading end telomeres is not known. TRF1 is proposed to repress ATR signaling in a BLM-independent manner using TIN2-bound TPP1/POT1 to prevent RPA accumulation on the G-rich telomeric DNA exposed when lagging strand DNA synthesis is impaired. The shown mechanism does not explain how TRF1 prevents ATR activation by

the single-stranded C-rich telomeric DNA. Exposed C-rich telomeric DNA (the leading strand template) will be adjacent to a 3' doublestranded-single-stranded transition, which is a suboptimal substrate for ATR activation. The position of the TRF1 complexes engaged in the proposed functions (drawn ahead of and behind the replication fork) is not known. The TRF1 complexes are likely connected to TRF2/Rap1 (not drawn) through their shared binding partner, TIN2. The stalled replisome is not depicted.

structures, promoting the integrity of lagging end telomeres only.

Given the many ways in which BLM contributes to genome maintenance (for review, see Chu and Hickson 2009), it is plausible that this helicase has multiple roles at telomeres, including ones that are independent of its interaction with TRF1. A case in point is the role of BLM in resolving ultrafine anaphase bridges (UFBs) at telomeres (Barefield and Karlseder 2012) as it does at late replicating regions and CFSs (Chan et al. 2009; Naim and Rosselli 2009). Unlike the dependence of BLM on TRF1 in promoting lagging end telomere replication, the targeting of BLM to telomeric UFBs does not require TRF1 (Barefield and Karlseder 2012).

As BLM is not required for the replication of leading end telomeres, it is clear that additional factors must assist TRF1 in preventing the fragile telomere phenotype. RTEL1 is a candidate for this function, as RTEL1 and BLM repress fragile telomeres in an additive manner that is on a par with the repression by TRF1 (Sfeir et al. 2009; Vannier et al. 2012). RTEL1 contains a proliferating cell nuclear antigen (PCNA)-interacting motif (Ding et al. 2004) that is required for the repression of the fragile telomere phenotype (Vannier et al. 2013). How TRF1 interacts with PCNA-bound RTEL1 to manage telomere replication merits further investigation, as do the roles of Timeless and Topoisomerase II $\alpha$ (Leman et al. 2012; d'Alcontres et al. 2014).

\section{TRF1-mediated and TPP1/POT1-mediated repression of replication stress-induced ATR signaling}

The data indicate that TRF1 represses ATR signaling using a BLM-independent mechanism that involves TIN2-dependent recruitment of the TPP1/POT1 heterodimers (Fig. 6). POTla has been proposed to compete with RPA for binding to single-stranded TTAGGG repeats either directly (Denchi and de Lange 2007; Gong and de Lange 2010) or with the aid of hnRNPA1 (Flynn et al. 2011). Exclusion of RPA from the single-stranded telomeric DNA should be sufficient to prevent the activation of ATR signaling, which requires the interaction of ATR-bound ATRIP with RPA (Zou and Elledge 2003). This model explains why ATR signaling is not detected at telomeres in BLM-deficient cells despite their telomere replication problems that are evident from the fragile lagging end telomeres.

However, as the POT1 proteins do not bind to the C-rich telomeric repeat strand, this model does not explain the absence of ATR signaling when telomere replication problems expose single-stranded CCCTAA repeats. In the unperturbed situation (when TRF1 is present), the fragile phenotype appears to primarily affect lagging end telomeres; activation of ATR by the singlestranded CCCTAA repeats may therefore not be a major threat. In addition, as optimal ATR activation requires a $5^{\prime}$ end at the double-stranded-single-stranded junction (MacDougall et al. 2007), the single-stranded CCCTTA repeats adjacent to the $3^{\prime}$ end of the leading strand may not activate the kinase efficiently. Finally, it could be argued that a modest level of ATR activation, perhaps by single-stranded CCCTAA repeats, is beneficial to ensure fork stability, while replication blocks are removed.

The model that TRF1-tethered TPP1/POT1 heterodimers can exclude RPA from the lagging strand template raises the question of whether RPA exclusion could be detrimental to DNA replication. RPA is thought to prevent/remove secondary structures that could impede DNA polymerase/ primase action. We imagine that on the single-stranded TTAGGG repeats, the engagement of the POT1 proteins could fulfill this role of RPA without hindering the replication fork.

We considered whether TRF1 deletion could also result in the loss of telomere terminus protection by TIN2/ TPP1/POT1. Several observations argue against this idea. First, TRF1 deletion does not provoke endoreduplication or deregulation of the telomeric overhangs and therefore fails to induce the full spectrum of POTla/b loss phenotypes (Hockemeyer et al. 2006; Sfeir et al. 2009). It could be argued that these two phenotypes only occur upon 
complete absence of POTla/b, whereas a modest reduction of POT1a/b at the telomere terminus, as might occur in the TRF1 knockout, could be sufficient to induce ATR signaling. This explanation seems unlikely, since previous work with TPP1 shRNAs showed that less TPP1 (and therefore presumably POTla/b) is required for ATR repression than for the control of the $3^{\prime}$ overhang (Hockemeyer et al. 2007). In addition, the ATR signaling in TRF1deficient cells is only apparent after their progression through S phase (Sfeir et al. 2009), whereas removal of all (or most) POT1a results in ATR activation in G1 as well as S/G2 (Gong and de Lange 2010). For these reasons, we propose that most of the ATR signaling in TRF1-deficient cells originates from sites of replication stress and not from the telomere termini.

\section{TRF1-mediated and TIN2/TPP1/POT1-mediated repression of sister telomere associations}

The data establish that TRF1 also employs TIN2/TPP1/ POT1 to repress sister telomere associations. These aberrant structures are not mediated by c-NHEJ and are potentially due to noncovalent interactions, such as strand invasion or unresolved Holliday junctions. We previously proposed that the sister telomere associations might be related to anaphase UFBs (Sfeir et al. 2009), but the current results argue against this, as BLM deficiency induces telomeric UFBs (Barefield and Karlseder 2012) but no sister telomere associations. Thus, the nature of sister telomere associations and their consequences remain to be determined.

It is noteworthy that the frequency of sister telomere associations is correlated with the level of ATR activation at telomeres (see Table 1), suggesting that they are generated by a process that is stimulated by this signaling pathway. In agreement, the frequency of sister telomere associations is significantly reduced when TRF1-deficient cells are treated with an shRNA to ATR (Sfeir et al. 2009). However, ATR activation is not sufficient to fully unleash this phenotype, since the frequency of sister telomere association, while significant, is low upon deletion of POT1a, TPP1, or TIN2 despite strong activation of the ATR pathway (Table 1). This low level of sister telomere associations could be related to the spontaneous replication problems known to occur in telomeres even when TRF1 is present. Therefore, we propose that the sister telomere associations represent a structure that results from an ATR-dependent transaction associated with replication fork arrest.

\section{Telomere replication problems and human health}

The potential impact of telomere replication problems on genome instability in cancer warrants further exploration. For instance, deletion of TRF1 in p53-deficient keratinocytes induces squamous cell carcinomas in mice (Martinez et al. 2009), and the breast cancer-associated human miR-155 targets TRF1 and causes fragile telomeres (Dinami et al. 2014). Furthermore, a mutation in RTEL1 that causes fragile telomeres accelerates tumorigenesis in p53-deficient mice, with the resulting tumor cells showing fragile telomeres and telomere fusions (Vannier et al. 2013).
However, whether fragile telomeres directly instigate genome instability and contribute to tumor progression is not yet clear.

The current data reveal a function for TIN2 in telomere replication that was not previously appreciated. TIN2 is known to stabilize shelterin and mediate the end protection functions of the POT1 proteins (for review, see Palm and de Lange 2008), and the TIN2 interaction with TPP1 is relevant with regard to telomerase function, since telomerase relies on its binding to TPP1 for association with telomeres (Abreu et al. 2010; Nandakumar et al. 2012; Zhong et al. 2012; Sexton et al. 2014). This list of TIN2-mediated functions can now be extended with its role in allowing the TPP1/POT1 heterodimers to repress ATR signaling during telomere replication and the accompanying association of sister telomeres.

TIN2 is mutated in dyskeratosis congenita (DC) and related disorders, causing severely shortened telomeres by a mechanism that is not fully understood (Savage et al. 2008; Walne et al. 2008; Sarper et al. 2010). As the TIN2$\mathrm{DC}$ mutations are in a region distinct from its interaction sites with TRF1, TRF2, and TPP1, it seems unlikely that the extremely short telomeres of TIN2 mutant DC patients are due to a severe deficiency in these interactions. Indeed, a mouse with a knock-in TIN2-DC mutation fails to show overt telomere dysfunction phenotypes (Frescas and de Lange 2014b). However, this mouse shows a slight telomere maintenance defect that cannot be ascribed to the lack of telomerase recruitment (Frescas and de Lange 2014b). It will therefore be important to exclude the possibility that some of the TIN2-DC phenotypes are due to fragile telomeres or sister telomere associations.

There are two other human telomere diseases in which fragile telomeres may play a role. First, the severe telomereshortening syndrome Coat's plus is caused by mutations in the Ctc1 component of the CST complex (Anderson et al. 2012). CST was shown to prevent the occurrence of fragile telomeres, presumably because it is involved in postreplicative copying of single-stranded TTAGGG repeats both at the telomere terminus and in gaps remaining in the duplex telomere repeat array (Stewart et al. 2012; Wang et al. 2012; Wu et al. 2012; Chen et al. 2013). Second, fragile telomeres can be caused by RTEL1 mutations that are associated with Hoyeraal-Hreidarsson syndrome, a severe form of DC (for review, see Vannier et al. 2014). Thus, it will be important to understand the extent to which the fragile telomere phenotypes arising from these mutations contribute to disease etiology.

Finally, the fragile telomere phenotype could be informative with regard to the events at the genome-wide CFSs. In particular, the strong lagging strand bias observed in BLMdeficient cells is a phenotype that is easily gleaned from CO-FISH of telomeres but is difficult to detect at most CFSs. As CFSs often lead to single chromatid aberrations, it is possible that these events actually represent CFSs where either the leading or lagging strand DNA synthesis is impaired. If such a bias were detected for a CFS, it would argue in favor of the DNA secondary structure being responsible for that particular CFS rather than a paucity of replication origins, which has been shown to contribute 
to the expression of the most active CFSs in human chromosomes (for review, see Debatisse et al. 2012).

\section{Materials and methods}

\section{Conditional knockout MEFs, cell culture, and expression} constructs

The $\mathrm{TRF}^{\mathrm{F} / \mathrm{F}}, \mathrm{BLM}^{\mathrm{F} / \mathrm{F}}, \mathrm{TPP}^{\mathrm{F} / \mathrm{F}}, \mathrm{Rap}^{\mathrm{F} / \mathrm{F}}, 53 \mathrm{BP} 1^{-/-}$, and ROSA Cre-ER ${ }^{\mathrm{T} 2}$ mice were published previously (Ward et al. 2003; Chester et al. 2006; Ventura et al. 2007; Sfeir et al. 2009, 2010; Kibe et al. 2010). MEFs from intercrosses were isolated from embryonic day 13.5 (E13.5) embryos, immortalized with retroviral pBabe-SV40-LT antigen (a gift from G. Hannon), and maintained as described previously (Celli and de Lange 2005). Conditional deletion of floxed alleles was induced by three retroviral infections with pMMP Hit\&Run Cre (Silver and Livingston 2001). For experimental time points, $t=0$ was set at $12 \mathrm{~h}$ after the first infection. Exogenous TRF1 and TIN2 alleles were introduced immediately prior to Cre treatment using two retroviral infections and in $2-3 \mu \mathrm{g} / \mathrm{mL}$ puromycin for $2-3 \mathrm{~d}$ (pLPC) or $90 \mu \mathrm{g} / \mathrm{mL}$ hygromycin for 5-6 d (pWZL).

Mutant TRF1 alleles were generated and inserted into pLPCNMYC using site-directed mutagenesis from mouse and human TRF1 cDNAs (Broccoli et al. 1997). pWZL-Flag-HA 2 -mTIN2 and pWZL-Flag-HA ${ }_{2}$-mTIN2-RCT were published previously (Frescas and de Lange 2014a).

\section{Immunoblotting and coimmunoprecipitations (co-IPs)}

Immunoblotting was carried out as previously described (Celli et al. 2006). For co-IPs, $2.5 \times 10^{6} 293 \mathrm{~T}$ cells were cotransfected with $10 \mu \mathrm{g}$ of each expression construct using $\mathrm{CaPO}_{4}$ precipitation and fed fresh medium after 7-8 h. After $24 \mathrm{~h}$, cells were collected by pipetting in ice-cold PBS and lysed for $40 \mathrm{~min}$ in 0.5 $\mathrm{mL}$ of cold PBS with $0.1 \%$ NP-40, 1 mM DTT, 1 mM PMSF, and protease inhibitors (Roche). After addition of $0.5 \mathrm{~mL}$ of PBS, the lysates were cleared by centrifugation. Aliquots of the supernatants were saved as input samples. Immunoprecipitations were performed on a nutator with $30 \mu \mathrm{L}$ (bed volume) of anti-Myc agarose affinity beads (Sigma-Aldrich) for $5 \mathrm{~h}$ at $4^{\circ} \mathrm{C}$ followed by three times with cold PBS. Proteins were released at $90^{\circ} \mathrm{C}$ in 60 $\mu \mathrm{L}$ of $2 \times$ Laemmli buffer and run on $4 \%-12 \%$ SDS-PAGE gels.

\section{Telomeric PNA-FISH and CO-FISH}

FISH and CO-FISH (Bailey et al. 1996) with telomeric PNA probes were performed as previously described (Celli et al. 2006). Cells were incubated with $0.2 \mu \mathrm{g} / \mathrm{mL}$ colcemid for $1 \mathrm{~h}$ for FISH, trypsinized, washed with medium containing serum and PBS, swollen in $0.075 \mathrm{M} \mathrm{KCl}$ for $15 \mathrm{~min}$ at $37^{\circ} \mathrm{C}$, fixed in ice-cold 3:1 methanol: acetic acid, and stored overnight at $4^{\circ} \mathrm{C}$. Metaphase spreads were dropped onto slides, aged overnight, rehydrated in PBS, fixed in $2 \%$ formaldehyde, treated with $1 \mathrm{mg}$ of pepsin per milliliter of $20 \mathrm{mM}$ glycine ( $\mathrm{pH} 2.0$ ) for $10 \mathrm{~min}$ at $37^{\circ} \mathrm{C}$, and again fixed with $2 \%$ formaldehyde. Slides were washed, dehydrated in an ethanol series, air-dried, and hybridized for $2 \mathrm{~h}$ at room temperature with the FITC-OO-[CCCTAA $]_{3}$ PNA probe (Applied Biosystems) in $70 \%$ formamide, $1 \mathrm{mg} / \mathrm{mL}$ blocking reagent (Roche), and $10 \mathrm{mM}$ Tris/ $\mathrm{HCl}(\mathrm{pH} 7.2)$ after a 5 -min denaturation at $80^{\circ} \mathrm{C}$. Slides were washed with $70 \%$ formamide in $10 \mathrm{mM}$ Tris $-\mathrm{HCl}(\mathrm{pH} 7.2)$ (twice for $15 \mathrm{~min}$ ) and in $0.1 \mathrm{M}$ Tris- $\mathrm{HCl}(\mathrm{pH} 7.0), 0.15 \mathrm{M} \mathrm{NaCl}$, and $0.08 \%$ Tween-20 (three times for $5 \mathrm{~min}$ ) with DAPI in the second wash. Slides were dehydrated in ethanol as above and mounted in ProLong gold anti-fade medium (Life Technologies).
For CO-FISH, cells were labeled with $10 \mu \mathrm{M} \operatorname{BrdU} / \operatorname{BrdC}$ (3:1) for $12-13 \mathrm{~h}$ prior to harvest. Metaphase spreads were prepared as above and rehydrated in PBS, and the BrdU/BrdC-substituted DNA strands were digested as described (Celli et al. 2006). DNA was hybridized in a sequential manner with TAMRA-OO$[\text { TTAGGG }]_{3}$ and FITC-OO-[CCCTAA $]_{3}$ PNA probes as above without heat denaturation. Slides were washed, dehydrated, and mounted as above.

\section{IF-FISH}

IF-FISH was performed as described before (Celli and de Lange 2005) with minor modifications. Paraformaldehyde-fixed cells on coverslips were permeabilized for $5 \mathrm{~min}$ in $0.1 \%$ Triton X-100, $20 \mathrm{mM}$ HEPES-KOH (pH 7.9), $50 \mathrm{mM} \mathrm{NaCl}, 3 \mathrm{mM} \mathrm{MgCl}$, and $300 \mathrm{mM}$ sucrose; washed twice with PBS for $5 \mathrm{~min}$; and blocked in PBG $(0.2 \%$ [w/v] cold-water fish gelatin [Sigma], 0.5\% [w/v] BSA [Sigma] in PBS) for $30 \mathrm{~min}$ at room temperature. Cover slips were incubated with primary antibody in PBG for $2 \mathrm{~h}$ at room temperature, washed three times with PBS for $5 \mathrm{~min}$, incubated with a fluorescently labeled secondary antibody for $1 \mathrm{~h}$ at room temperature, washed three times in PBS for $5 \mathrm{~min}$, fixed with $3 \%$ paraformaldehyde for $5 \mathrm{~min}$ at room temperature, and washed three times with PBS for $5 \mathrm{~min}$. A FITC-OO-[CCCTAA $]_{3}$ PNA probe (Applied Biosystems) dissolved in $70 \%$ formamide, $1 \mathrm{mg} / \mathrm{mL}$ blocking reagent (Roche), and $10 \mathrm{mM}$ Tris- $\mathrm{HCl}(\mathrm{pH} 7.2)$ was added. After denaturation $\left(7 \mathrm{~min}\right.$ at $\left.80^{\circ} \mathrm{C}\right)$, hybridization was for $2 \mathrm{~h}$ at room temperature followed by washes in $70 \%$ formamide, $10 \mathrm{mM}$ Tris-HCl (pH 7.2), and PBS.

\section{ChIP}

Telomeric ChIP was performed as described previously (Loayza and de Lange 2003; Frescas and de Lange 2014b) with minor modifications. Cells were rinsed with PBS and cross-linked with $15 \mathrm{~mL}$ of $1 \%$ formaldehyde for $30 \mathrm{~min}$ at room temperature. Cross-linking was stopped with $2 \mathrm{~mL}$ of $1.5 \mathrm{M}$ glycine for $5 \mathrm{~min}$, and the cells were washed and scraped into $10 \mathrm{~mL}$ of cold PBS. Cell suspensions were processed for immunoprecipitations $(15 \mu \mathrm{L}$ of crude rabbit anti-TRF1 1449 or the preimmune control), crosslinks were reversed, and the DNA was purified, dot-blotted, and detected by hybridization as previously described (Frescas and de Lange 2014b). ChIP signals were normalized to the total DNA signal in the input samples.

\section{Analysis of telomeric overhang by in-gel hybridization}

Single-stranded telomeric DNA was quantified by in-gel hybridization as described previously (Celli and de Lange 2005) using MboI-digested genomic DNA embedded in agarose plugs fractionated on a CHEF gel. The gel was dried and hybridized under native conditions with a ${ }^{32} \mathrm{P}$ end-labeled $[\mathrm{CCCTAA}]_{3}$ probe to obtain the single-stranded telomeric overhang signal. After denaturation and rehybridization with the same probe, the singlestranded telomeric DNA signal in the 9- to $150-\mathrm{kb}$ range was quantified using ImageQuant and normalized to the total telomeric DNA signal in the same lane.

\section{Antibodies}

The following antibodies were used for immunoblotting and IF at the indicated dilutions: rabbit anti-TRF1 1449 (1:2000), rabbit antiBLM Ab2179 (1:500; Abcam), rabbit anti-TIN2 1447 (1:2000), rabbit anti-53BP1 NB100-304 (1:1000; Novus Biologicals), mouse antiMyc 9E10 (1:1000; Cell Signaling), mouse anti-Flag M2 (1:1000; 
Sigma-Aldrich), mouse anti- $\gamma \mathrm{H} 2 \mathrm{AX}$ JBW301 (1:1000; Millipore), mouse anti-HA 12CA5 (1:1000; Roche), and mouse anti- $\gamma$-Tubulin GTU-88 (1:10,000; Sigma-Aldrich).

\section{Acknowledgments}

We gratefully acknowledge Devon White for expert mouse husbandry. We thank Philip Leder for his generous gift of the $\mathrm{BLM}^{\mathrm{F} / \mathrm{F}}$ mice, and Sara Buonomo for the human GFP-BLM construct. We thank Agnel Sfeir for her involvement in the initial stages of this work. Agnel Sfeir and members of the de Lange laboratory are thanked for comments on this manuscript. This work was supported by grants from the National Institutes of Health to T.d.L. (5R37GM49046 and 5RO1AG16642). T.d.L. is an American Cancer Society Research Professor. M.Z. was supported by the Brno PhD Talent fellowship and grants to Dr. Ctirad Hofr from the Czech Ministry of Education, Youth, and Sports; American Science Information Center (LH13054); Czech Science Foundation (GACR P205/12/0550); and European Regional Development Fund (CZ.1.05/1.1.00/02.0068 and CZ.1.07/ 2.3.00/30.0019).

\section{References}

Abreu E, Aritonovska E, Reichenbach P, Cristofari G, Culp B, Terns RM, Lingner J, Terns MP. 2010. TIN2-tethered TPP1 recruits human telomerase to telomeres in vivo. Mol Cell Biol 30: 2971-2982.

Anderson BH, Kasher PR, Mayer J, Szynkiewicz M, Jenkinson EM, Bhaskar SS, Urquhart JE, Daly SB, Dickerson JE, O'Sullivan J, et al. 2012. Mutations in CTC1, encoding conserved telomere maintenance component 1 , cause Coats plus. Nat Genet 44: 338-342.

Bachrati CZ, Borts RH, Hickson ID. 2006. Mobile D-loops are a preferred substrate for the Bloom's syndrome helicase. Nucleic Acids Res 34: 2269-2279.

Bailey SM, Goodwin EH, Meyne J, Cornforth MN. 1996. COFISH reveals inversions associated with isochromosome formation. Mutagenesis 11: 139-144.

Barefield C, Karlseder J. 2012. The BLM helicase contributes to telomere maintenance through processing of late-replicating intermediate structures. Nucleic Acids Res 40: 7358-7367.

Bosco N, de Lange T. 2012. A TRF1-controlled common fragile site containing interstitial telomeric sequences. Chromosoma 121: 465-474.

Broccoli D, Chong L, Oelmann S, Fernald AA, Marziliano N, van Steensel B, Kipling D, Le Beau MM, de Lange T. 1997. Comparison of the human and mouse genes encoding the telomeric protein, TRF1: chromosomal localization, expression and conserved protein domains. Hum Mol Genet 6: 69-76.

Bryan TM, Baumann P. 2011. G-quadruplexes: from guanine gels to chemotherapeutics. Mol Biotechnol 49: 198-208.

Celli GB, de Lange T. 2005. DNA processing is not required for ATM-mediated telomere damage response after TRF2 deletion. Nat Cell Biol 7: 712-718.

Celli GB, Lazzerini Denchi E, de Lange T. 2006. Ku70 stimulates fusion of dysfunctional telomeres yet protects chromosome ends from homologous recombination. Nat Cell Biol 8: 885890.

Chan KL, Palmai-Pallag T, Ying S, Hickson ID. 2009. Replication stress induces sister-chromatid bridging at fragile site loci in mitosis. Nat Cell Biol 11: 753-760.

Chen Y, Yang Y, van Overbeek M, Donigian JR, Baciu P, de Lange T, Lei M. 2008. A shared docking motif in TRF1 and TRF2 used for differential recruitment of telomeric proteins. Science 319: 1092-1096.
Chen LY, Majerska J, Lingner J. 2013. Molecular basis of telomere syndrome caused by CTC1 mutations. Genes Dev 27: 2099-2108.

Chester N, Babbe H, Pinkas J, Manning C, Leder P. 2006. Mutation of the murine Bloom's syndrome gene produces global genome destabilization. Mol Cell Biol 26: 6713-6726.

Chong L, van Steensel B, Broccoli D, Erdjument-Bromage H, Hanish J, Tempst P, de Lange T. 1995. A human telomeric protein. Science 270: 1663-1667.

Chu WK, Hickson ID. 2009. RecQ helicases: multifunctional genome caretakers. Nat Rev Cancer 9: 644-654.

d'Alcontres MS, Palacios JA, Mejias D, Blasco MA. 2014. TopoI $\alpha$ prevents telomere fragility and formation of ultra thin DNA bridges during mitosis through TRF1-dependent binding to telomeres. Cell Cycle 13: 1463-1481.

Debatisse M, Le Tallec B, Letessier A, Dutrillaux B, Brison O. 2012. Common fragile sites: mechanisms of instability revisited. Trends Genet 28: 22-32.

de Lange T. 2009. How telomeres solve the end-protection problem. Science 326: 948-952.

Denchi EL, de Lange T. 2007. Protection of telomeres through independent control of ATM and ATR by TRF2 and POT1. Nature 448: 1068-1071.

Dinami R, Ercolani C, Petti E, Piazza S, Ciani Y, Sestito R, Sacconi A, Biagioni F, le Sage C, Agami R, et al. 2014. miR-155 drives telomere fragility in human breast cancer by targeting TRF1. Cancer Res 74: 4145-4156.

Ding H, Schertzer M, Wu X, Gertsenstein M, Selig S, Kammori M, Pourvali R, Poon S, Vulto I, Chavez E, et al. 2004. Regulation of murine telomere length by Rtel: an essential gene encoding a helicase-like protein. Cell 117: 873-886.

Diotti R, Loayza D. 2011. Shelterin complex and associated factors at human telomeres. Nucleus 2: 119-135.

Flynn RL, Centore RC, O'Sullivan RJ, Rai R, Tse A, Songyang Z, Chang S, Karlseder J, Zou L. 2011. TERRA and hnRNPA1 orchestrate an RPA-to-POT1 switch on telomeric singlestranded DNA. Nature 471: 532-536.

Frescas D, de Lange T. 2014a. TRF2-tethered TIN2 can mediate telomere protection by TPP1/POT1. Mol Cell Biol 34: 13491362.

Frescas D, de Lange T. 2014b. A TIN2 dyskeratosis congenita mutation causes telomerase-independent telomere shortening in mice. Genes Dev 28: 153-166.

Frescas D, de Lange T. 2014c. Binding of TPP1 to TIN2 is required for POT1a,b-mediated telomere protection. I Biol Chem 289: 24180-24187.

Gong Y, de Lange T. 2010. A Shld1-controlled POT1a provides support for repression of ATR signaling at telomeres through RPA exclusion. Mol Cell 40: 377-387.

Greider CW, Blackburn EH. 1985. Identification of a specific telomere terminal transferase activity in Tetrahymena extracts. Cell 43: 405-413.

He H, Wang Y, Guo X, Ramchandani S, Ma J, Shen MF, Garcia DA, Deng Y, Multani AS, You MJ, et al. 2009. Pot1b deletion and telomerase haploinsufficiency in mice initiate an ATRdependent DNA damage response and elicit phenotypes resembling dyskeratosis congenita. Mol Cell Biol 29: 229240.

Hockemeyer D, Daniels JP, Takai H, de Lange T. 2006. Recent expansion of the telomeric complex in rodents: two distinct POT1 proteins protect mouse telomeres. Cell 126: 63-77.

Hockemeyer D, Palm W, Else T, Daniels JP, Takai KK, Ye JZ, Keegan CE, de Lange T, Hammer GD. 2007. Telomere protection by mammalian POT1 requires interaction with TPP1. Nat Struct Mol Biol 14: 754-761. 
Hockemeyer D, Palm W, Wang RC, Couto SS, de Lange T. 2008. Engineered telomere degradation models dyskeratosis congenita. Genes Dev 22: 1773-1785.

Huber MD, Lee DC, Maizels NP. 2002. G4 DNA unwinding by BLM and Sgslp: substrate specificity and substrate-specific inhibition. Nucleic Acids Res 30: 3954-3961.

Kibe T, Osawa GA, Keegan CE, de Lange T. 2010. Telomere protection by TPP1 is mediated by POT1a and POT1b. Mol Cell Biol 30: 1059-1066.

Kim SH, Kaminker P, Campisi J. 1999. TIN2, a new regulator of telomere length in human cells. Nat Genet 23: 405-412.

Leman AR, Dheekollu J, Deng Z, Lee SW, Das MM, Lieberman PM, Noguchi E. 2012. Timeless preserves telomere length by promoting efficient DNA replication through human telomeres. Cell Cycle 11: 2337-2347.

Lillard-Wetherell K, Machwe A, Langland GT, Combs KA, Behbehani GK, Schonberg SA, German J, Turchi J, Orren DK, Groden J. 2004. Association and regulation of the BLM helicase by the telomere proteins TRF1 and TRF2. Hum Mol Genet 13: 1919-1932.

Loayza D, de Lange T. 2003. POT1 as a terminal transducer of TRF1 telomere length control. Nature 424: 1013-1018.

Luo G, Santoro IM, McDaniel LD, Nishijima I, Mills M, Youssoufian H, Vogel H, Schultz RA, Bradley A. 2000. Cancer predisposition caused by elevated mitotic recombination in Bloom mice. Nat Genet 26: 424-429.

MacDougall CA, Byun TS, Van C, Yee MC, Cimprich KA. 2007. The structural determinants of checkpoint activation. Genes Dev 21: 898-903.

Machwe A, Xiao L, Groden J, Orren DK. 2006. The Werner and Bloom syndrome proteins catalyze regression of a model replication fork. Biochemistry 45: 13939-13946.

Machwe A, Karale R, Xu X, Liu Y, Orren DK. 2011. The Werner and Bloom syndrome proteins help resolve replication blockage by converting (regressed) Holliday junctions to functional replication forks. Biochemistry 50: 6774-6788.

Martinez P, Thanasoula M, Munoz P, Liao C, Tejera A, McNees C, Flores JM, Fernandez-Capetillo O, Tarsounas M, Blasco MA. 2009. Increased telomere fragility and fusions resulting from TRF1 deficiency lead to degenerative pathologies and increased cancer in mice. Genes Dev 23: 2060-2075.

Mohaghegh P, Karow JK, Brosh RMJ, Bohr VA, Hickson ID. 2001. The Bloom's and Werner's syndrome proteins are DNA structure-specific helicases. Nucleic Acids Res 29: 2843 2849.

Naim V, Rosselli F. 2009. The FANC pathway and BLM collaborate during mitosis to prevent micro-nucleation and chromosome abnormalities. Nat Cell Biol 11: 761-768.

Nandakumar J, Bell CF, Weidenfeld I, Zaug AJ, Leinwand LA, Cech TR. 2012. The TEL patch of telomere protein TPP1 mediates telomerase recruitment and processivity. Nature 492: $285-289$.

Nimonkar AV, Ozsoy AZ, Genschel J, Modrich P, Kowalczykowski SC. 2008. Human exonuclease 1 and BLM helicase interact to resect DNA and initiate DNA repair. Proc Natl Acad Sci 105: 16906-16911.

Nimonkar AV, Genschel J, Kinoshita E, Polaczek P, Campbell JL, Wyman C, Modrich P, Kowalczykowski SC. 2011. BLMDNA2-RPA-MRN and EXO1-BLM-RPA-MRN constitute two DNA end resection machineries for human DNA break repair. Genes Dev 25: 350-362.

Palm W, de Lange T. 2008. How shelterin protects mammalian telomeres. Annu Rev Genet 42: 301-334.

Ralf C, Hickson ID, Wu L. 2006. The Bloom's syndrome helicase can promote the regression of a model replication fork. J Biol Chem 281: 22839-22846.
Rizzo A, Salvati E, Porru M, D'Angelo C, Stevens MF, D'Incalci M, Leonetti C, Gilson E, Zupi G, Biroccio A. 2009. Stabilization of quadruplex DNA perturbs telomere replication leading to the activation of an ATR-dependent ATM signaling pathway. Nucleic Acids Res 37: 5353-5364.

Sarper N, Zengin E, Kilic SC. 2010. A child with severe form of dyskeratosis congenita and TINF2 mutation of shelterin complex. Pediatr Blood Cancer 55: 1185-1186.

Savage SA, Giri N, Baerlocher GM, Orr N, Lansdorp PM, Alter BP. 2008. TINF2, a component of the shelterin telomere protection complex, is mutated in dyskeratosis congenita. Am I Hum Genet 82: 501-509.

Sexton, AN, Regalado SG, Lai CS, Cost GJ, O’Neil CM, Urnov FD, Gregory PD, Jaenisch R, Collins K., Hockemeyer D. 2014. Genetic and molecular identification of three human TPP1 functions in telomerase action: recruitment, activation, and homeostasis set point regulation. Genes Dev 28: $1885-1899$.

Sfeir A, Kosiyatrakul ST, Hockemeyer D, MacRae SL, Karlseder J, Schildkraut CL, de Lange T. 2009. Mammalian telomeres resemble fragile sites and require TRF1 for efficient replication. Cell 138: 90-103.

Sfeir A, Kabir S, van Overbeek M, Celli GB, de Lange T. 2010. Loss of Rap1 induces telomere recombination in the absence of NHEJ or a DNA damage signal. Science 327: 1657-1661.

Silver DP, Livingston DM. 2001. Self-excising retroviral vectors encoding the Cre recombinase overcome Cre-mediated cellular toxicity. Mol Cell 8: 233-243.

Stewart JA, Wang F, Chaiken MF, Kasbek C, Chastain PD, Wright WE, Price CM. 2012. Human CST promotes telomere duplex replication and general replication restart after fork stalling. EMBO J 31: 3537-3549.

Sun H, Karow JK, Hickson ID, Maizels NP. 1998. The Bloom's syndrome helicase unwinds G4 DNA. I Biol Chem 273: 27587-27592.

Takai H, Smogorzewska A, de Lange T. 2003. DNA damage foci at dysfunctional telomeres. Curr Biol 13: 1549-1556.

Takai KK, Kibe T, Donigian JR, Frescas D, de Lange T. 2011. Telomere protection by TPP1/POT1 requires tethering to TIN2. Mol Cell 44: 647-659.

van Brabant AJ, Ye T, Sanz M, German JL, Ellis NA, Holloman WK. 2000. Binding and melting of D-loops by the Bloom syndrome helicase. Biochemistry 39: 14617-14625.

Vannier JB, Pavicic-Kaltenbrunner V, Petalcorin MI, Ding H, Boulton SJ. 2012. RTEL1 dismantles T loops and counteracts telomeric G4-DNA to maintain telomere integrity. Cell 149: 795-806.

Vannier JB, Sandhu S, Petalcorin MI, Wu X, Nabi Z, Ding H, Boulton SJ. 2013. RTEL1 is a replisome-associated helicase that promotes telomere and genome-wide replication. Science 342: 239-242.

Vannier JB, Sarek G, Boulton SJ. 2014. RTEL1: functions of a disease-associated helicase. Trends Cell Biol 24: 416-425.

Ventura A, Kirsch DG, McLaughlin ME, Tuveson DA, Grimm J, Lintault L, Newman J, Reczek EE, Weissleder R, Jacks T. 2007. Restoration of p53 function leads to tumour regression in vivo. Nature 445: 661-665.

Walne AJ, Vulliamy T, Beswick R, Kirwan M, Dokal I. 2008. TINF2 mutations result in very short telomeres: analysis of a large cohort of patients with dyskeratosis congenita and related bone marrow failure syndromes. Blood 112: 35943600.

Wang F, Stewart JA, Kasbek C, Zhao Y, Wright WE, Price CM. 2012. Human CST has independent functions during telomere duplex replication and C-strand fill-in. Cell Reports 2: 1096-1103. 
Ward IM, Minn K, van Deursen J, Chen J. 2003. p53 binding protein $53 \mathrm{BP} 1$ is required for DNA damage responses and tumor suppression in mice. Mol Cell Biol 23: 2556-2563.

Wu L, Hickson ID. 2003. The Bloom's syndrome helicase suppresses crossing over during homologous recombination. Nature 426: 870-874.

Wu P, Takai H, de Lange T. 2012. Telomeric 3' overhangs derive from resection by Exol and Apollo and fill-in by POT1bassociated CST. Cell 150: 39-52.

Zhong FL, Batista LF, Freund A, Pech MF, Venteicher AS, Artandi SE. 2012. TPP1 OB-fold domain controls telomere maintenance by recruiting telomerase to chromosome ends. Cell 150: 481-494.

Zou L, Elledge SJ. 2003. Sensing DNA damage through ATRIP recognition of RPA-ssDNA complexes. Science 300: 15421548. 


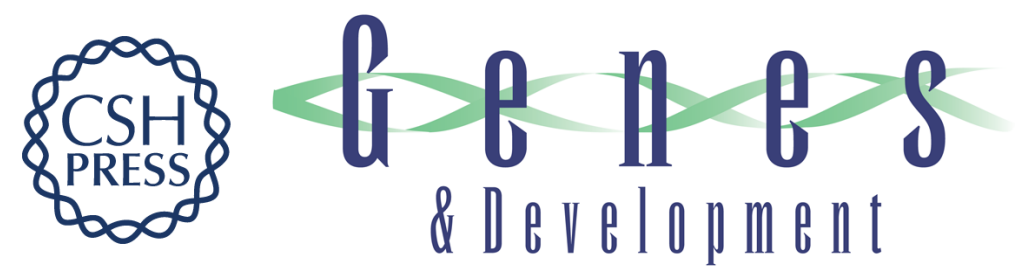

\section{TRF1 negotiates TTAGGG repeat-associated replication problems by recruiting the BLM helicase and the TPP1/POT1 repressor of ATR signaling}

Michal Zimmermann, Tatsuya Kibe, Shaheen Kabir, et al.

Genes Dev. 2014, 28: originally published online October 24, 2014

Access the most recent version at doi:10.1101/gad.251611.114

Supplemental Material

References

Creative

Commons

License

Email Alerting

Service
http://genesdev.cshlp.org/content/suppl/2014/10/23/gad.251611.114.DC1

This article cites 74 articles, 26 of which can be accessed free at: http://genesdev.cshlp.org/content/28/22/2477.full.html\#ref-list-1

This article, published in Genes \& Development, is available under a Creative Commons License (Attribution-NonCommercial 4.0 International), as described at http://creativecommons.org/licenses/by-nc/4.0/.

Receive free email alerts when new articles cite this article - sign up in the box at the top right corner of the article or click here.

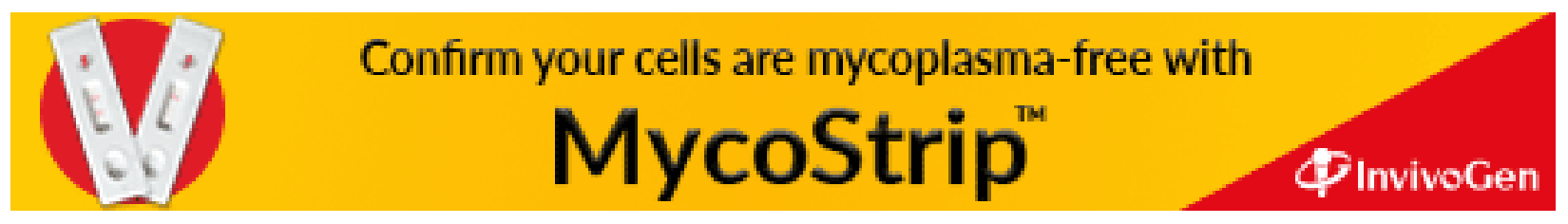

